\title{
ARTÍCULOS
}

\section{REDESCUBRIMIENTO DE LOS PLEITOS JUDICIALES DE UNA TEMPRANA SOCIEDAD COLONIAL. CORRIENTES, RÍO DE LA PLATA (1588-1680).}

\author{
Fátima Valenzuela \\ CONICET \\ fatima val@live.com.ar \\ Fernando Pozzaglio \\ CONICET \\ fearpozzaglio@gmail.com
}

Resumen: En este artículo nos proponemos explorar el fondo judicial del Archivo General de la Provincia de Corrientes. Por un lado, desarrollaremos un catálogo de las causas judicializadas entre 1612 y 1680 , es decir, un instrumento descriptivo que puede ser utilizado por historiadores y/usuarios del archivo. Por otro lado, caracterizaremos los pleitos que corresponden a los albores de la configuración de la ciudad de San Juan de Vera. En ese contexto, presentaremos una primera lectura en torno al funcionamiento de la justicia ordinaria y el accionar de otros funcionarios reales en el espacio colonial. De ese modo, lograremos una aproximación a los discursos y experiencias por medio de las causas judiciales.

Palabras clave: Fondo judicial, siglo XVII, Corrientes, Archivo General de la Provincia de Corrientes, justicia ordinaria, causas civiles, causas criminales.

Tittle: REDISCOVERY OF THE LAWSUITS OF AN EARLY COLONIAL SOCIETY. CORRIENTES, RÍO DE LA PLATA (1588-1680).

Abstract: In this article we propose to explore the judicial fund of the General Archive of the Province of Corrientes. On the one hand, we will develop a catalog of judicial cases between 1612 and 1680, that is, a descriptive instrument that can be used by other historians and users of the archive. On the other hand, we characterize the lawsuits that took place at the dawn of the configuration of the city of San Juan de Vera. In this context, we will develop a first reading about the operation of ordinary justice and the action of other royal officials in the colonial space. In this way, we get an approximation to discourses and experiences through judicial cases.

Keywords: Judicial fund, $17^{\text {th }}$ century, Corrientes, General Archive of the Province of Corrientes, ordinary justice, civil cases, criminal cases.

Cómo citar este artículo: VALENZUELA, Fátima y POZZAGLIO, Fernando. Redescubrimiento de los pleitos judiciales de una temprana sociedad colonial. Corrientes, Río de la Plata (1588-1680). Naveg@mérica. Revista electrónica editada por la Asociación Española de Americanistas [en línea]. 2020, n. 25. Disponible en: <http://revistas.um.es/navegamerica>. [Consulta: Fecha de consulta]. ISSN 1989-211X. 


\section{Introducción}

El archivo judicial es "una acumulación de hoja suelta tras hoja suelta, de demandas, procesos, interrogatorios, informaciones y sentencias" ${ }^{1}$. Este fondo, a diferencia de otras series documentales, ha sido resignificado por el valor y atractivo de los papeles que conserva, pues esos permiten explorar la cotidianeidad del mundo colonial con sus entramados, conflictos y minucias. Específicamente, permite adentrarse en "un universo donde adquieren protagonismo los condenados, los miserables y lo malos sujetos; o sea las víctimas, demandantes, sospechosos o delincuentes"2. De ese modo, el archivo judicial exhibe los pliegos de la vida de los más desfavorecidos.

Tomando esas premisas en este artículo exploramos el fondo judicial que se atesora en el Archivo General de la Provincia de Corrientes. Este potente corpus documental presenta una característica distintiva, su escaso tratamiento que le dieron historiadores colonialistas. Estos legajos permanecían olvidados y sin ser trabajados a raíz de la inexistencia de un catálogo o inventario de los casos y, sobre todo, por su estado de conservación. Nuestra hipótesis de trabajo asevera que los investigadores locales no consultaron estos fondos, porque implicaba un complejo proceso de lectura que insumía muchas horas a raíz de la ausencia de instrumentos descriptivos pertinentes ${ }^{3}$.

En esta propuesta ${ }^{4}$, en un primer momento, realizamos un trabajo de identificación y de organización de la tipología documental, que dio como resultado la elaboración de un primer catálogo de cada una de las causas o pleitos identificables correspondientes al siglo XVII ${ }^{5}$. El catálogo discrimina los pleitos civiles y los criminales.

En un segundo momento, exploramos los motivos o razones que exponían los pleitos, además de indagar los actores involucrados y las posibles resoluciones. La visualización completa de las causas permitió, desde un enfoque social, reflexionar y analizar cuáles eran las principales tensiones que existían en la temprana sociedad correntina, $y$, desde el enfoque institucional, explorar el funcionamiento de la justicia ordinaria a la luz de la actuación de los funcionarios que intervenían en dichas causas o pleitos.

\footnotetext{
${ }^{1}$ FARGE, Arlette. La atracción del archivo. Institucio Valenciana D’Estudis i Investigacio; Edicicions Alfons El Magnanim, 1991, p. 8.

${ }^{2}$ Ibídem, p. 8.

${ }^{3}$ Esta situación fue una constante con otros fondos como ser protocolos notariales o documentos de gobierno, que presentan una reducida utilización por historiadores clásicos del siglo XX.

${ }^{4}$ Una primera aproximación sobre el trabajo en torno al fondo judicial se ha presentado en: SALINAS, María Laura y VALENZUELA, Fátima. Fondos judiciales y Humanidades digitales en espacio periféricos del Imperio español. El Archivo General de la provincia de Corrientes, Argentina. Siglos XVII-XIX. Temas Americanistas. Jun. 2019, n. 42, pp. 138-159.

5 Esta investigación se enmarca en un proyecto de investigación más amplio denominado: Digitalización, conservación y uso de las fuentes judiciales en la historia colonial correntina. Este proyecto es dirigido por la Dra. María Laura Salinas y está financiado por la Secretaría General de Ciencia y Técnica de la Universidad Nacional del Nordeste. En esta oportunidad, nos interesará comunicar un primer avance en los procesos de catalogación y descripción, tareas que desarrollamos en el período que se extiende en la primera mitad del siglo XVII.
} 


\section{El Archivo General de la Provincia de Corrientes, una primera caracterización general}

Antes de abocarnos al fondo judicial y al inventario que elaboramos, nos interesa caracterizar al Archivo General de la Provincia de Corrientes (en adelante AGPC) ${ }^{6}$ con el fin de explicar en qué contexto surge nuestro trabajo archivístico e histórico.

El AGPC se creó por normativa del Congreso provincial en 1821. La temprana creación manifestó "una clara conciencia archivística y un interés permanente por el pasado próximo"7. Isidoro Martínez y Cires, Ramón de Galarraga y Ciriaco Roa constituyeron la comisión que se eligió para que procediera a la organización del archivo local. Francisco Rojas fue nombrado posteriormente, durante el gobierno de Pedro Ferré, para el ordenamiento y atención del archivo.

Desde el siglo XIX, la idea de organizar, clasificar e inventariar estuvieron presentes en los funcionarios y especialistas correntinos. El gobierno provincial deseaba dar orden, decencia y seguridad para la custodia y conservación de los documentos que él contiene. Don Teodoro Gauna y José Francisco Atienza emprendieron las tareas de formar "un inventario de los expedientes, protocolos y cualesquiera otra clase de documentos que se hallen en el archivo, poniendo al margen el número progresivo que le corresponda; clasificar y hacer la debida separación según el orden a que pertenezca, poner en cada uno de ellos un pequeño membrete con el número que le haya tocado en el inventario general”.".

En la primera mitad del siglo XX, se llevaron adelante numerosas tareas de organización de fondos documentales, que no se modificaron con el tiempo. En ese contexto debemos mencionar que participaron en esta labor don Ismael Grosso y los doctores Manuel Bonastre, Ramón Díaz de Vivar y Julio G. Guastavino. La tarea de Ismael Grosso fue clasificar unos 63703 expedientes y 3087 libros distribuidos en 3058 legajos conteniendo alrededor de 1.883 .797 fojas. Como señala Enrique Schaller, "el ordenamiento no contempló la división en fondos, secciones, series o colecciones. Los documentos fueron clasificados en fondos organizados de acuerdo con las diversas actividades desempeñadas por el gobierno provincial"'.

En la segunda mitad del siglo XX, surgieron cambios vinculados a la localización del archivo. En 1986, su director Doctor Héctor Bóo donó el terreno definitivo ubicado en la calle Carlos Pellegrini 1385. En ese momento, también, se dieron

\footnotetext{
6 Para ampliar la caracterización del AGPC, ver: POZZAGLIO, Fernando Ariel; MORENO CABANILLAS Rocío y SVRIZ WUCHERER, Pedro Miguel Omar. Fuentes y tipos documentales para reconstruir la historia de la ciudad de Corrientes durante la época colonial. REFA. Revista Electrónica de Fuentes y Archivos. 2018, año 9, n. 9, pp. 97-117.

${ }^{7}$ LEONI, María Silvia y QUIÑÓNEZ, María Gabriela, Debates y polémicas en la conformación del campo historiográfico correntino a fines del siglo XIX. Anuario del Instituto de Historia Argentina. 2015, n. 15, p. 2.

${ }^{8}$ PALMA, Federico. Archivos correntinos. Corrientes: Universidad Nacional del Nordeste, 1967, p. 9.

${ }^{9}$ SCHALLER, Enrique César. Fuentes para el estudio de la economía, sociedad y organización estatal en el nordeste argentino en la etapa colonial e independiente. La documentación del Archivo de la Provincia de Corrientes. REFA. Revista Electrónica de Fuentes y Archivos. 2019, año 10, n. 10, p. 62.
} 
transformaciones en torno a la incorporación de fondos documentales que se recibieron de los archivos locales del interior de la provincia y, sobre todo, de la transferencia ejecutada por los archivos administrativos emplazados en la capital correntina. Inicialmente los fondos correspondían al período colonial y a la época nacional; pero, con el paso del tiempo, se han ido incorporando fondos del período contemporáneo.

En la actualidad, el AGPC atesora gran parte de la documentación de la ciudad y provincia de Corrientes correspondiente al período colonial (1588-1810) y la mayor parte de la correspondiente a la época nacional (1810-1960). Según Ernesto Maeder, este archivo constituyó el repositorio más rico de todo el litoral argentino para la época colonial, con la sola excepción del Archivo General de la Nación.

Entre las series documentales correspondientes al periodo colonial podemos hallar los documentos de gobierno (1570-1809), las actas capitulares (1588-1824); Fundación de pueblos (1588-1810), Temporalidades (1639-1738), Protocolos (15901810), expedientes judiciales (1641-1850) y papeles del Extinguido Convento de Santo Domingo (1775).

\subsection{La organización y la descripción documental en los fondos coloniales del AGPC. Necesidades y urgencias}

Los fondos coloniales se encuentran encuadernados en grandes legajos. Cada encuadernación está realizada con tapas rígidas y rústicas de cartón, que se componen de unos 230 o 260 folios cosidos en el lomo. Por esa razón, cada legajo se encuentra dentro de un folio y ha estado allí al menos unos ochenta años. Cuando se tomó esa decisión, quizás las ideas de conservación del momento, motivaron a la noción de "guardar en folios" a los documentos como una estrategia de protección y resguardo de los documentos. A simple vista, se observa que se han destinado numerosos fondos financieros para esa tarea, pero esto no ha sido suficiente para su conservación.

En términos de organización y descripción de los fondos, el archivo presenta escasos instrumentos de descripción y de control con los que disponen los usuarios o incluso el mismo personal administrativo. Para la mayoría de los fondos coloniales y los más contemporáneos se han elaborado unas rústicas listas en donde se presentan los tomos secuenciados por años temporales ${ }^{10}$. Estas listas no llegan a constituir un inventario de los fondos, porque solo recogen información referida a los años en donde se extienden los tomos individualizados. Pero con estas, los usuarios, podemos identificar los años extremos o máximos de los fondos, no obstante, resultan insuficientes a la hora de constituirse en instrumentos de descripción documental. Al no saber lo que puede presentar cada tomo, se debe proceder a una lectura pormenorizada para ahondar en el conocimiento de su contenido.

\footnotetext{
${ }^{10}$ Estas listas han sido elaboradas por un antiguo archivero de la institución, están mecanografiadas y disponibles al público. Ese mismo archivero había desarrollado diferentes tareas como una transcripción parcial de las actas capitulares, documento que se encontró hace pocos años; y también, había empezado a desarrollar un inventario para los expedientes administrativos correspondientes al siglo XIX.
} 
Luego de exponer la falta de instrumentos descriptivos, surgen nociones en torno a las necesidades y urgencias a la luz del estado de los fondos del AGPC. En esas necesidades y/o urgencias que afectan las tareas de investigación de los historiadores se encuadran las acciones emprendidas en el fondo judicial, uno de los tantos fondos sobre los cuales es posible y perentorio desarrollar un trabajo minucioso y sistematizado de elaboración de un catálogo.

\section{El redescubrimiento del fondo judicial correntino, una lectura historiográfica y situada}

"En lengua castellana, lo judicial es aquello relativo o atinente al juicio, y por extensión, son judiciales las huellas que deja esa actividad y que los historiadores podemos convertir en fuentes"11. En el campo historiográfico argentino, por influencias europeas, se produjo el redescubrimiento del archivo judicial a partir de estudios en los cuales se buscaban reconstruir a los sectores subalternos desde su vida cotidiana hasta la criminalización de sus conductas $^{12}$. En este sentido, los historiadores sociales llegaban a las fuentes judiciales con el fin de comprender conflictos sociales, procesos económicos o representaciones culturales. Años más tarde, nuevas preguntas e intereses centrados en los procedimientos de la administración de la justicia y en los usos que de estos hicieron los diferentes actores sociales, obligaron a redescubrir las fuentes judiciales en profundidad. En la actualidad, el campo historiográfico que hace uso de estas fuentes es profuso y no se circunscribe solo al período colonial, sino que transciende las temporalidades ${ }^{13}$.

En el territorio correntino, las fuentes judiciales constituían un fondo casi inexplorado en los estudios clásicos correntinos. No obstante, en las últimas décadas, investigaciones centradas en los sectores subalternos fueron visibilizando el fondo judicial correntino, observando sus particularidades, estructura y organización.

Durante mucho tiempo, los fondos judiciales se guardaron en el Archivo de los Tribunales de Corrientes, institución que se definía como un repositorio bien organizado y registrado. Recién en 1965, los protocolos y causas civiles y criminales fueron relocalizados en las instalaciones del AGPC.

El fondo judicial correntino es un robusto conjunto de documentos, de enorme dimensión y extensión, semejante a los protocolos notariales y documentos de gobierno. Los expedientes judiciales están organizados en unos 323 tomos con unas 300 fojas cada uno, lo que da por resultado unas 96900 fojas aproximadamente. Siguiendo los datos aportados por los rústicos índices, encontramos que existen 16 tomos del siglo XVII, unos 100 tomos del XVIII y unos 206 tomos $^{14}$ de la primera

\footnotetext{
${ }^{11}$ BARRIERA, Darío. Historia y justicia. Cultura, política y sociedad en el Río de la Plata (Siglos XVIXIX). Buenos Aires: Prometeo Libros, 2019, p. 96.

12 BARRIERA, Darío. Justicias, jueces y culturas jurídicas en el siglo XIX rioplatense. Nuevo Mundo Mundos Nuevos. 2010.

${ }^{13}$ Ver: MOLINA, Eugenia. Tras los pasos de la justicia. Algunos aportes de la historiografía de la justicia para el Río de la Plata tardocolonial y republicano temprano en relación con los procesos de estatalidad. PolHIS. Jul./Dic. 2015, año 8, n. 16, pp. 126-157.

14 Tomo 1 (1619-1658), Tomo 2 (1658-1660), Tomo 3 (1660-1664), Tomo 4 (1664-1666), Tomo 5
} 
mitad del XIX.

El fondo judicial se presenta como un gran cúmulo de papeles en donde el investigador puede ir pesquisando causas de diferente naturaleza. A diferencia de otros archivos históricos, el fondo judicial correntino no tiene series documentales ${ }^{15}$ identificables a priori, que hayan surgido en el momento de creación de la documentación. Esta situación lo diferencia de otros fondos judiciales que existen en otras ciudades, donde, por ejemplo, subsisten diferentes series ${ }^{16}$.

Dentro del fondo judicial, las unidades documentales simples son legajos que refieren a procesos civiles y criminales. Sin embargo, el usuario debe ir encontrando a cada una de ellas, dado que no contamos con un inventario o catálogo de las causas. La falta de un catálogo pormenorizado de las causas, procesos, litigios, actores y resoluciones produce que el acceso a este corpus este limitado e incluso anule su utilización por parte de interesados.

El estado de conservación de los documentos es muy deficiente, lo cual es señalado por el actual director del archivo, quien sostiene que la documentación existente son "papeles amarillentos, manuscritos opacos, manchados, con rasgaduras y perforaciones que se nos presentan con diversos grados de deterioro, a veces más parecidos a un encaje que a una hoja... legajos asaltados por la humedad y los ácaros durante siglos...".

En este sentido, hemos hallado que muchas de las fojas de los distintos tomos se encuentran atacadas por bacterias, hongos y gérmenes lo que dificulta la lectura y el manejo de la documentación judicial.

Por esa razón, emprendimos un trabajo de digitalización con un grupo de investigación dirigido por la Dra. María Laura Salinas y numerosos profesionales ${ }^{17}$.

(1666-1670), Tomo 6 (1670-1672), Tomo 7 (1672), Tomo 8 (1672-1673), Tomo 9 (1672-1681), Tomo 10 (1682-1683), Tomo 11 (1684-1689), Tomo 12 (1689-1693), Tomo 13 (1694-1696), Tomo 14 (16961697), Tomo 15 (1698-1699), Tomo 16 (1699-1702), continúa.

15 "Las series son subdivisiones del fondo, identificada con la producción documental de una unidad o división administrativa o funcional de la institución que produce el fondo. Las series están identificadas con las funciones o con los órganos productoras de documentos". Ver: HEREDIA HERRERA, Antonia. Archivística general. Teoría y práctica. 5o ed. actualizada. Sevilla: Servicios de publicaciones de la Diputación, 1991, p. 143.

${ }^{16}$ En el Archivo Histórico de Córdoba, existen cinco series dentro del fondo de justicia. Nos referimos a la Escribanía 1, Escribanía 2, Escribanía 3, Escribanía 4 y Escribanía de Crimen. Ver: González Navarro, Constanza, 2017, 28. En el Archivo General de la Nación, el cuadro de clasificación establece instituciones políticas y judiciales donde en el fondo cabildo, justicia y regimiento de Buenos Aires, aparece el sub-fondo tribunales. En este sub-fondo, integran 4 series: juzgado del crimen, juzgado civil, santa hermandad y defensoría de menores.

${ }^{17}$ El proceso de digitalización es un intenso trabajo que lo desarrollamos en el Archivo junto con el equipo de investigación. Se han digitalizado siete tomos de los fondos judiciales, lográndose captar unas 1287 imágenes. Debemos señalar que esta tarea la están desarrollando un grupo de becarios de forma intensiva. La digitalización está siendo dirigida por el Prof. Ricardo Olivieri y desarrollada por los profesores: Milagros Blanco, José Neziz, Joaquín Cleva y Nicolás Molina. La tarea es supervisada por archivistas que hacen el control de calidad de la documentación digitalizada. Esta tarea de digitalización es fundamental para el trabajo posterior de reconocimiento de cada uno de los legajos correspondientes a los pleitos, en donde intervienen paleógrafos especializados en la documentación colonial. 
Esta digitalización constituye un trabajo de resguardo del material, como instancia central para la conservación y manipulación futura de la documentación. En relación a esta tarea, nuestro primer acercamiento nos obligó a preguntarnos si era posible generar un inventario $\mathrm{y} / \mathrm{o}$ catálogo que permitiera el uso de los expedientes judiciales. Esa cuestión nos llevó a pensar cómo se producen y generan esos instrumentos descriptivos, qué datos o variables deben incluir y cómo construir inventarios que sean válidos para otros historiadores o posibles usuarios de este fondo. Todas esas preguntas nos llevaron a revisar otros ejemplos producidos por historiadores o archivistas en nuestra región, a fin de poder desarrollar una propuesta válida y holística.

\section{Algunos antecedentes pasados y presentes en la formulación de instrumentos descriptivos. Una tarea producida por archivistas e historiadores}

Las tareas de reunir, catalogar, ordenar y difundir los documentos son las funciones centrales y básicas de los archivos y archiveros. Un archivo es la suma de tres elementos: Documentos + organización + servicio ${ }^{18}$. La organización y elaboración de instrumentos que facilitan el acceso a los fondos ha sido una de las actividades desplegadas por los archiveros; no obstante, muchas veces han contribuido a estas, los historiadores. En situaciones concretas, los historiadores principales usuarios de los archivos- han emprendido tareas vinculadas a la producción de catálogos, índices o guías. En este apartado, analizaremos algunos rasgos centrales de los instrumentos descriptivos y registraremos algunos casos en donde los historiadores produjeron una labor descriptiva valiosa. El análisis de estos instrumentos es vital para la creación de uno pertinente para el fondo judicial.

En el mundo de la archivística, "la labor descriptiva se orienta a hacer accesible los fondos documentales del archivo" "'. Los instrumentos tienen como fin revelar el contenido y el carácter de los documentos y facilitar su localización, ya que deben estar al alcance de los usuarios. Así existen una diversidad de instrumentos descriptivos: las guías, los inventarios y los catálogos.

- Guías: "proporcionan información sobre todos o partes de los fondos de uno o más archivos, se describe globalmente las grandes agrupaciones documentales, se esboza la historia de los organismos productores y facilitan información auxiliar de los archivos y sus servicios"20.

- Inventarios: "describen las unidades que componen las series documentales, según el cuadro de clasificación y reproduciendo su estructura. La elaboración de un inventario condensa la actividad intelectual del trabajo sobre el fondo documental, su clasificación y descripción, aunados con la doble finalidad: conocer qué es lo que se tiene y cómo está organizado ${ }^{21}$. De esa forma, el inventario brinda información sobre el contenido y la localización. Existen, según Cruz Mundet, inventarios someros y analíticos.

\footnotetext{
${ }_{18}^{18}$ HEREDIA HERRERA, Antonia. Archivística general. Teoría y práctica... Op. cit., p. 89.

${ }^{19}$ CRUZ MUNDET, José Ramón. Manual de archivística. Madrid: Pirámide, 1994.

${ }^{20}$ CRUZ MUNDET, José Ramón. Manual de archivística. Op. cit., p. 273.

${ }^{21}$ CRUZ MUNDET, José Ramón. Manual de archivística. Op. cit., p. 276.
} 
Los últimos son los que describen los fondos con mayor profundidad al descender hasta los expedientes.

- Catálogos: "tienen la finalidad de describir exhaustivamente las piezas documentales y las unidades archivísticas. La elaboración del catálogo implica incluir una descripción referida a la identidad, contenido/estructura, al tipo de material y a las condiciones de acceso y utilización"22 .

¿Qué pasa cuando todos estos instrumentos no están elaborados? Quizás una de las problemáticas centrales de los archivos es que no se hayan elaborado los instrumentos de descripción adecuada. Si llegamos a esa conclusión, surge una cuestión que interpela al historiador, un frecuente usuario del archivo, que es la necesidad de elaborarse algunos de esos instrumentos para acceder a los fondos, series y unidades documentales simples o compuestas.

La problemática del archivo no fue ajena al historiador, $y$, muchas veces, ha debido ejercer y generar acciones vinculadas a la valoración, selección, catalogación y el acceso ${ }^{23}$. En la búsqueda de mejorar la utilización de los fondos documentales, los historiadores han desarrollado tareas de descripción, es decir, elaboraron instrumentos que facilitan el acceso a los fondos ${ }^{24}$. También existen otros recorridos en los cuales los historiadores elaboraron sus propios inventarios a raíz de sus trabajos cotidianos, y, tras años de trabajo, han publicado para compartir dicha información. En estos casos, no se usaron las normas archivísticas, pero formularon documentación útil que podía ser transferible a otros investigadores.

En el nordeste argentino, se han logrado elaborar varias guías referidas a los archivos locales y regionales producidas por historiadores del siglo XX. Estos escritos no tomaron el nombre de guías, pero fueron investigaciones que brindaron consideraciones generales sobre los fondos, series e información valiosa sobre los archivos.

En la década de 1920, se produjo la primera guía de los archivos correntinos, la cual recogía información sobre la historia del archivo y un listado de los fondos más importantes. Del mismo modo, esta guía brindaba datos inestimables sobre el estado edilicio y las tareas de conservación propias de la época ${ }^{25}$. El documento descriptivo fue elaborado por un miembro del Instituto de Investigaciones Históricas de la Facultad de Filosofía y Letras, Eduardo Fernández Olguín, quien fuera

\footnotetext{
${ }^{22}$ CRUZ MUNDET, José Ramón. Manual de archivística. Op. cit., p. 282.

${ }^{23}$ Un buen análisis en estos términos constituye la propuesta de Angélica Corva, Rastreando huellas. La búsqueda de documentos judiciales para la investigación histórica. Revista Electrónica de Fuentes y Archivos. 2015, n. 6, pp. 43-65.

${ }^{24}$ Un ejemplo constituye el trabajo desarrollado en el Archivo Histórico de la provincia de Córdoba, donde un grupo de investigación emprendido la tarea de organizar y catalogar el fondo judicial. En ese proyecto, participaron investigadores de la Escuela de Archivología de la Universidad Nacional de Córdoba e historiadores. El proyecto se denominó Prácticas de producción, ordenamiento y conservación del fondo de justicia colonial de Córdoba y estuvo integrado por la Dra. Constanza González Navarro (Dir.), el Dr. Silvano Benito Moya, las Dra. Beatriz Bixio, Andrea Giomi, Romina Grana, María Marschoff, Gabriela Parra Garzón, Noelia Silvetti y Justo Tapia.

${ }^{25}$ OLGUín FERNÁNDEZ, Eduardo. Los archivos de la ciudad de Corrientes. Buenos Aires. Publicaciones de la Sección de Historia. Facultad de Filosofía y Letras. 1921, n. VIII.
} 
miembro de la nueva escuela histórica ${ }^{26}$, institución que comenzaba a emprender tareas en torno al estudio de la organización de los archivos de provincias argentinas.

La segunda guía fue elaborada, en la década del 60, por Federico Palma ${ }^{27}$, reconocido hombre de la cultura y de la historia en la región. Su documento manifestaba mayor información del estado de los fondos documentales del AGPC, dado que ejerció la función de director de esta institución y del Boletín Oficial de la provincia de Corrientes.

La última guía que podemos mencionar para los archivos regionales es la que elaboró Ernesto Maeder titulado Relevamiento de los fondos documentales de los archivos de la región Nordeste Argentina y de Asunción del Paraguay ${ }^{28}$. Este escrito es quizás el documento más completo sobre los archivos, sus fondos, series, ubicación y/o horario de atención.

En el caso de los inventarios y catálogos, los historiadores crearon instrumentos descriptivos pensados o estructurados en torno a temas específicos. Estas producciones no siempre fueron fieles a los principios de la archivística, dado que no se detuvieron en una descripción pormenorizada de todas las unidades documentales simples que se conservaban en una serie o fondo documental. La mayoría de las veces seleccionaban o listaban los documentos que revelaban un interés en torno a un problema de investigación concreto. Por ejemplo, podemos mencionar dos casos: el primero, Fuentes documentales, bibliotecas públicas y privadas en el Paraguay para el estudio de las dos guerras de Adelina Pusineri y, segundo, Documentos jesuíticos del siglo XVIII en el Archivo Nacional de Asunción redactado por Ignacio Telesca. El escrito por Pusineri es un ejemplo de una guía de archivos, bibliotecas y colecciones referidos a la Guerra del Chaco y Guerra de la Triple Alianza, en donde se analizan los fondos más importantes de los archivos paraguayos que resguardan documentos referidos a esos temas ${ }^{29}$. El segundo caso es un estudio sobre las fuentes sobre los jesuitas que se conservan en el Archivo

\footnotetext{
${ }^{26}$ La Nueva Escuela Histórica se organizó a partir de 1916, sus miembros historiadores profesionales se focalizaron en el trabajo de archivo y en la publicación-divulgación de fuentes inéditas. Estos eran el insumo indispensable para que la tarea de los historiadores fuera plenamente científica. Ver: DEPETRIS, Nicolás. Visiones del pasado: la Nueva Escuela Histórica y los positivistas. Sociales y Virtuales. 2019, vol. 6, n. 6.

${ }^{27}$ Fue miembro de la Academia Nacional de la Historia en 1970; también fue nombrado miembro correspondiente de diversas juntas de historia de Santa Fe, Catamarca, Chaco, Tucumán, Mendoza y Entre Ríos, del Instituto de Investigaciones Históricas de Santiago del Estero, de la Asociación Argentina de Estudios Históricos, del Instituto Histórico de la Organización Nacional y del Instituto de Ciencias Genealógicas; fue presidente de la Asociación Archivística correntina. Ver: SOLIS CARNICER, María del Mar. Entre la tradición y la renovación historiográfica. Federico Palma y su contribución a la historiografía correntina contemporánea. En: MAEDER, Ernesto; LEONI, M. Silvia y QUIÑONEZ, M. Gabriela. Visiones del Pasado. Estudios de Historiografía de Corrientes. Corrientes: Moglia, 2004, pp. 109-157.

28 MAEDER, Ernesto. Relevamiento de los fondos documentales de los archivos de la región Nordeste Argentina y de Asunción del Paraguay. Revista de Estudios Regionales. 1978, pp. 7-61.

${ }^{29}$ PUSINERI, Adelina. Estado de las fuentes documentales y bibliotecas públicas y privadas en el Paraguay para el estudio de las dos guerras. Nuevo Mundo Mundos Nuevos [en línea]. 2006. Disponible en <http://journals.openedition.org/nuevomundo/2187>.
} 
Nacional de Asunción; en torno a eso, se recuperan los documentos compuestos que permanecen en distintas series documentales -propiedades y testamentos, sección historia, sección nueva encuadernación, civil y judicial, actas capitulares, copias-. El trabajo asume la tarea de caracterizar brevemente cada documento compuesto alojado en diferentes series ${ }^{30}$.

Por fuera de estos ejemplos, existen trabajos de mayor envergadura, como el Catálogo de la Sección Historia elaborado por Andrea Tutté y Norma Ibañez de Yegros $^{31}$. Este catálogo refleja el contenido real de la documentación de la sección, su estado de conservación y/ su perdida. El usuario cuenta con un registro de todos los documentos que están presentes en el fondo. Este trabajo ha llevado mucho más tiempo en su construcción y elaboración, además de constituir un trabajo colectivo emprendido en el Archivo Nacional de Asunción.

Como fue expuesto, tanto los historiadores como los archivistas han realizado instrumentos descriptivos de los archivos. Si bien los historiadores han hecho trabajos que pueden ser criticados dado que no siguieron las normativas de la ciencia archivística, debe destacarse que para sus contextos de producción, han sido valiosos aportes en situaciones desfavorables. Lograron crear o gestionaron instrumentos de descripción útiles que favorecieron las tareas de investigación tanto otros profesionales como, así también, para los propios archivos. En la propuesta que nos interesa ahondar buscaremos presentar un catálogo que hemos desarrollado para el fondo judicial, que se ajuste al principio de procedencia y a su ordenación natural.

\section{Clarificando el órgano producto del fondo judicial correntino en el período colonial}

Una tarea de descripción documental implica un proceso de deconstrucción del fondo judicial correntino para lo cual es necesario aclarar el funcionamiento del organismo productor de esa documentación. Preliminarmente debemos señalar cómo funcionaba el mundo judicial, político y cultural del periodo colonial que le da sentido.

"En las ciudades hispanoamericanas -que desde la perspectiva hispánica pertenecían a los Reinos de Indias-, el Cabildo -la congregación de vecinos- fue la sede del poder político, la sede de la administración de los recursos de la ciudad y también la del ejercicio de la justicia en primera instancia para sus naturales y residentes durante todo el período colonial"32. La normativa señalaba que "la justicia estaba en manos de los alcaldes, portadores de la vara" ${ }^{\text {"3 }}$. Imagen que los trabajos

\footnotetext{
30 TELESCA, Ignacio. Documentos jesuíticos del siglo XVIII en el Archivo Nacional de Asunción. Asunción: Centro de estudios paraguayos, 2006.

${ }_{31}$ TUTTE, Andrea. Catálogo de la Sección Historia del Archivo Nacional. Asunción: Tiempo de Historia, 2008.

${ }^{32}$ BARRIERA, Darío. La ciudad y las varas: justicia, justicias y jurisdicciones. Siglo XVI-XVII. Revista de Historia del Derecho. 2003, n. 31, pp. 75-76.

${ }_{33}$ BARRIERA, Darío. Abrir las puertas de la tierra. Microanálisis de la construcción de un espacio político. Santa Fe, 1573-1640. $2^{\circ}$ ed. Santa Fe: Ministerio de Innovación y Cultura de la Provincia de Santa Fe; Museo histórico provincial, 2017.
} 
históricos han sido capaces de refutar a la luz del análisis de actas del cabildo y legajos de los pleitos sostenidos que permiten explorar la coexistencia de varas de justicia, de justicias en plural $^{34}$.

La vara era, el signo del imperio de la justicia del rey y de la delegación de la potestad de administrar justicia en el regio nombre por parte de quien fuera su portador. En las ciudades, las varas de la justicia la poseían "los alcaldes de corte, los corregidores, sus tenientes y alcaldes, los juezes pesquisadores, los alguaciles y los demás ministros de justicia”.

El alcalde de primer voto fue la pieza clave de la administración de la justicia ordinaria de la monarquía hispánica durante el Antiguo Régimen. Pieza clave, sí: pero no siempre preeminente. Mucho menos, excluyente. "El alcalde debía guardar la equidad -el derecho a las partes-, principio de la justicia distributiva, que daba a cada quien lo que le correspondía según su status"35. También estaba facultado a impartir justicia en primera instancia en pleitos sostenidos entre indios y españoles.

Los Sumarios de la Recopilación General de las Leyes Occidentales de 1628 sostenían en la ley primera que "en cada pueblo de españoles, aya, y se elijan dos alcaldes ordinarios, en la forma que tienen de costumbres: los quates tengan la jurisdicción ordinaria, civil y criminal, y de ellos se apele para la Audiencias, Gobernadores o Cabildos..."36.

En la praxis, el ejercicio de la justicia en el orden local descansaba, también, en los lugartenientes de adelantados o gobernadores. No había preeminencia del alcalde sobre el teniente o gobernador, sino como sostiene Tau Anzoátegui: "Quien primero conocía desplazaba al otro. La elección de una u otra vía vario en el tiempo...". En cambio, Zacarías Moutokías propone que la intervención de uno y otro dependía de la gravedad del delito en cuestión. Estas situaciones podemos comprobar y corroborar en el accionar judicial que se desliza en los pleitos correntinos.

El adelantado, al igual que el corregidor, eran considerados justicias mayores, estas autoridades reunían dignidad y residencia en un lugar o sede, las potestades ligadas al gobierno con las implicancias de oficios de justicia sin más. El termino justicia mayor no significaba que sea una justicia de segunda instancia o que constituyera en un tribunal de apelación, sino que era justicia mayor por su dignidad que se imponía en preeminencia al alcalde ${ }^{37}$.

Con el avance efectivo en los territorios americanos de la Monarquía, el sistema institucional y jurídico antes mencionado para el espacio de la ciudad empezó a ser insuficiente. En las campañas rurales, se estableció una regulación y ejercicio efectivo de las jurisdicciones a la hora de gobernar administrar justicia. En esos espacios, aparecieron diferentes dispositivos para afirmar el dominio como ser curas

\footnotetext{
${ }^{34}$ BARRIERA, Darío. La ciudad y las varas... Op. cit., p. 76.

${ }^{35}$ BARRIERA, Darío. Abrir las puertas de la tierra. Op. cit., p. 141.

${ }^{36}$ BARRIERA, Darío. Abrir las puertas de la tierra. Op. cit., p. 143.

${ }^{37}$ BARRIERA, Darío. Abrir las puertas de la tierra. Op. cit., p. 147.
} 
doctrineros, comandantes de frontera, reducciones, fortines, curatos, alcaldías de Santa Hermandad, comisionados, pedáneos, partidos y distrito.

Una figura jurisdiccional de baja justicia que se destacó en el grupo de agentes: el oficio del alcalde de Santa Hermandad. Este apareció en los cabildos rioplatenses a comienzos del siglo XVII y se consolidó en el siglo XVII. En la real cédula de 1546, se les daba a los alcaldes la designación de ordinarios y de santa hermandad, lo que los habilitaba para proceder sumariamente en los casos que ocurrieran fuera de la urbe. En 1555, la Monarquía permitió el nombramiento de alcaldes de santa hermandad, estos tenían atribuciones judiciales menores, lo que significaba administrar justicia sumaria in situ. O sea, podían resolver la mayor parte de los conflictos en forma oral; si el pleito involucraba un monto económico superior a los 50 pesos debía intervenir el alcalde ordinario de la ciudad. En caso de homicidio, debían llevar el sumario a la ciudad y poner a disposición el reo ${ }^{38}$.

En el siglo XVIII, la tarea de los alcaldes de Santa Hermandad fueron complementadas por la implementación de otras figuras específicas como los jueces comisionados y jueces pedáneos. Estos cambios se dieron a raíz de los cambios y reformas producidos por los Borbones y la aplicación de la Real Ordenanza de Intendentes ${ }^{39}$.

Tras considerar este breve panorama del funcionamiento local de la justicia, analizaremos algunos rasgos en la ciudad de Corrientes.

\subsection{La administración de justicia en Corrientes}

La ciudad de Corrientes fue una ciudad subalterna en la que los lugartenientes 0 tenientes de gobernador asumían las atribuciones de gobierno, además de las funciones de justicia y guerra, en calidad de los oficios de justicia mayor y capitán a guerra que desempeñaban. Mientras que como capitanes a guerra se hallaban facultados para dirigir las milicias locales, en su función de justicia mayor entendían como jueces de primera de primera instancia en los asuntos ordinarios. Los tenientes de gobernador eran nombrados por los gobernadores que residían en Buenos Aires, capital del Río de la Plata, provincia menor que dependía de la Audiencia de Charcas y formaba parte del Virreinato del Perú.

No obstante, la pieza clave en la ciudad de Corrientes fue el cabildo que ocupó un rol central en la vida de la jurisdicción. Sus alcaldes ordinarios, elegibles anualmente, tenían a su cargo la administración de la justicia en primera instancia, tanto en los asuntos civiles como criminales. "Estos eran jueces legos, con conocimientos básicos del sistema judicial, exigiéndoseles únicamente a los vecinos que ocupaban este cargo que supieran leer y escribir y tener más de 25 años ${ }^{\prime 40}$.

\footnotetext{
${ }^{38}$ BARRIERA, Darío. Justicias rurales: el oficio de alcalde de la hermandad entre el derecho, la historia y la historiografía (Santa Fe, Gobernación del Río de la Plata, siglos XVII a XIX). Andes, 2013.

39 Ver: BARRIERA, Darío, Instituciones, justicias de proximidad y derecho local en un contexto reformista. Revista de Historia del Derecho Sección Investigaciones. Jul./Dic. 2012, n. 44, pp. 1-28.

${ }^{40}$ POZZAGLIO, Fernando. El cabildo y la elite en Corrientes, desde la fundación hasta 1782 [tesis doctoral]. Buenos Aires: Universidad del Salvador, 2015, p. 48.
} 
"Las dimensiones de la jurisdicción y el poblamiento de la campaña plantearon en el siglo XVIII la necesidad de extender la administración de justicia y ciertas funciones de policía a los partidos rurales"41. Al principio, dichas tareas estaban asignadas a los alcaldes de Santa Hermandad ${ }^{42}$, nombrados por el Cabildo; no obstante, se crearon en su lugar los jueces comisionados de la campaña que compartieron su jurisdicción con los alcaldes de Santa Hermandad. En 1756, se efectuaron las primeras designaciones para el pago de Ensenadas; en 1758 para el pago de Riachuelo y en 1759 para Empedrado y San Lorenzo.

Finalmente, el cabildo definió la esfera de competencia de los alcaldes de la santa hermandad y de los jueces comisionados: los primeros debían administrar justicia en la campaña y oír demandas hasta en cantidad de 200 pesos, podían otorgar poderes para testar y los testamentos en casos de urgencia; en cambio, los segundos debían ser nombrados ante la falta de los alcaldes y debían entender en causas urgentes y no en otra manera.

Con el proceso revolucionario e independentista, Corrientes experimentó una transición en materia jurídica ${ }^{43}$. Por muchos años, se mantuvo la estructura jurídica heredada del Antiguo Régimen que implicaba que los alcaldes de primer y segundo voto administraran justicia según la concepción castellano-indiana. Recién en 1821 se aprobó el Reglamento Constitucional, en el cual se determinó la independencia absoluta de la Administración de Justicia del gobierno.

\section{Un catálogo para el fondo judicial correntino. Un proceso de deconstrucción para la generalización de variables pertinentes}

Podemos señalar que los resultados que se presentan aquí discurren entre la definición de inventario-catálogo. Si en un principio pensamos en generar un inventario como un mero registro del fondo judicial, poco a poco, observamos que nos interesaba desarrollar un trabajo más profundo que diera cuenta del conocimiento alcanzado del fondo explorado. Ese trabajo nos condujo a la elaboración de un primer catálogo de causas o litigios del período que transcurre entre 1612 y 1680.

La elaboración de un catálogo implica un proceso cognoscitivo más profundo ${ }^{44}$, en el cual se emprendió:

a) fase heurística de individualización de cada una de las unidades documentales compuestas que constituían el pleito;

b) fase analítica o de elaboración de fichas descriptivas;

c) fase de síntesis que determinó la producción final del catálogo.

\footnotetext{
${ }^{41}$ MAEDER, Ernesto. Historia económica de Corrientes en el periodo virreinal. 1776-1810. Buenos Aires: Academia Nacional de la Historia, 1981, p. 154.

${ }^{42}$ En otros territorios, se crearon y multiplicaron los alcaldes de Santa Hermandad como en Buenos Aires o Tucumán.

${ }^{43}$ El funcionamiento del cabildo correntino fue estudiado por Fernando Pozzaglio, op.cit.

${ }^{44}$ Ver: PAGÁN, Ester Alba. Catálogo e inventario como instrumentos para la gestión del patrimonio cultural. En: Jornada "Educació i formació en torn al patrimoni cultural de l'interior". Xàtiva, 11 de diciembre de 2013.
} 
En otros términos, podemos señalar que tras un proceso de digitalización, de la lectura de cada uno de los expedientes que se conservan en el fondo judicial, del reconocimiento pormenorizado que implicó un inventario preliminar, se procedió a definir la organización de un catálogo de los litigios ${ }^{45}$.

Este catálogo se estructura en función de diversas cuestiones vinculadas al propio proceso o litigio judicial:

1. Año de producción de la causa.

2. Materia de la causa: civil-criminal.

3. Motivo del pleito.

4. Nombre del demandado.

5. Nombre del demandante.

6. Autoridades intervinientes.

Por fuera de esos elementos centrales, el catálogo tiene en cuenta otros elementos secundarios que dan cuenta de la unidad documental compuesta que configura el expediente estudiado:

$<$ Elementos que se incorporan a la causa: testigos, documentación probatoria

$<$ Sentencia.

$<$ Posibles apelaciones.

Esta posible generalización de variables, es una manera adecuada de estructurar la catalogación del fondo. En ese sentido, nos interesa señalar que todas las variables elegidas han sido pensadas en función del uso que puede realizar un historiador y/o especialista a la hora de recabar información pertinente sobre los litigios o pleitos.

En términos archivísticos, las normas ISAD-G ${ }^{46}$ sostienen que una unidad documental simple o compuesta debe ser identificada teniendo en cuenta: nombre del fondo, el código del fondo, el asunto o contenido de la unidad documental y la signatura. En nuestro trabajo, apelamos a las normas pero también presentamos una posibilidad que surge del trabajo histórico pormenorizado en el fondo.

La elaboración de un catálogo lo pensamos como una actividad colaborativa para otros historiadores e incluso para el mismo archivo que necesita contar con instrumentos descriptivos a fin de brindar un servicio al usuario.

\subsection{Una mirada hacia el interior de las causas judiciales}

Entre 1588-1680, el fondo judicial correntino presenta unas 86 causas o pleitos que llegaron a la justicia de primera instancia. En principio debemos señalar que las primeras causas judiciales corresponden a las primeras décadas del siglo XVII, con

\footnotetext{
${ }^{45} \mathrm{Al}$ final del trabajo, se anexa el catálogo elaborado en función de las variables centrales.

${ }^{46}$ Las normas ISAD-G son normas internacionales que se han establecido para la elaboración de descripciones archivísticas. Estas tienen como finalidad la identificación y explicación el contexto y el contenido de los documentos de archivo con el fin de hacerlos accesible.
} 
lo cual, no contamos con pleitos de los primeros años de la ciudad de San Juan de Vera.

Las causas civiles suman unas 79 mientras que las criminales se reducen a unas 7. En esta primera clasificación apelamos a la identificación que aparece en la documentación y, en algunos casos, procedimos a una definición realizada por nosotros.

\section{a) Las causas civiles}

"En 1660, se presentaba el capitán Don Martín de Vera en nombre de doña Petronila de Geres y Garnica, viuda mujer que fue legitima del generoso Felipe Argarañas y Mugica ya difunto encomendero que fue de la provincia de Tucumán de los indios mogosnas para que recoja, cobre y reduzca todos los indios de dichas naciones y encomiendas que quedaron en la ciudad de San Juan de Vera"47, este caso de concesión de un poder para que se administre a los indios era uno de los tantos pleitos que involucraban a encomenderos/as con administradores locales en donde la tensión se centraba en la posesión de los indios en encomienda que estaban reducidos en pueblos muy cercanos a la ciudad. Poderes de encomiendas, presentaciones por encomiendas vacas, reclamos por posesión de encomiendas eran algunas de las causas civiles que encabezaban los pleitos de los tempranos años de la ciudad.

Más allá de los indios encomendados, las cartas de obligación que se firmaban entre particulares y sellaban actos económicos eran otra constante en los pleitos civiles. A veces, solo aparecían las cartas y otras veces aparecían los reclamos por los incumplimientos en torno a esas. "En 1665 el alférez Cristóbal González, vecino de Santa Fe le daba una carta de obligación a Domingo de Quintana para pasar unas 2017 cabezas de ganado que debía remitir por año y medio"48. En relación a las cartas de obligación, aparecían los poderes para representar a terceros en otras ciudades vecinas como Santa Fe, Asunción o Buenos Aires. Y por último, aparecían los incumplimientos económicos que podían genera embargos o largos litigios porque una de las partes se veía afectaba. Por ejemplo, "Juan de Sosa señalaba que pedía y tenía un embargo de haber satisfecho a Hernando Díaz por mandado el trabajo de tres caballos y un peón que le alquilo a los campos del Uruguay"49.

Las causas civiles remitían a los derechos que la naturaleza le concede al hombre, los cuales giran en torno al estado de las personas, la familia, las obligaciones-contrato, las cosas, la posesión y la propiedad, y las sucesiones ${ }^{50}$.

En ese sentido, los pleitos se desarrollaban por diferentes motivos: la disputa de bienes gananciales a raíz de testamentarias, deudas por pagos incumplidos de productos de la tierra (ganado, carretas, aguardientes), conflictos por títulos de

\footnotetext{
${ }^{47}$ AGPC. Sala I. Judiciales. Tomo 2. Fojas 237-244.

${ }^{48}$ AGPC. Sala I. Judiciales. Tomo 5.

${ }^{49}$ AGPC. Sala I. Judiciales. Tomo 6. Foja 40-52.

50 Seguimos los planteamientos de LEVAGGI, Abelardo. Manual de Historia del derecho argentino. Tomo II. Buenos Aires: LexisNexis, 2005.
} 
encomienda o posesión de indios, disputas por solares o tierras, venta de oficios capitulares, entre otras muchas causas. En estos casos, eran los particulares que se presentaban ante el alcalde de primer voto y solicitaban el resarcimiento de sus derechos y/o propiedades.

Los litigios civiles nos llevan a establecer una serie de nociones claves para la época, como "los derechos de propiedad". La historia se inicia con una merced o sea concesión de un título de propiedad sobre tierras realengas otorgadas a un personaje influyente, o con la adquisición de una parcela. No obstante, conviven numerosos derechos en torno a la propiedad como ser derechos comunales, mayorazgos, dominios directos e indirectos. El concepto de propiedad debe ser entendido en forma relacional e histórica. En el Antiguo Régimen, tenemos que abandonar el significante de "una propiedad", noción liberal decimonónica por la frase conceptual "derechos de propiedad", que implica una noción plural e histórica ${ }^{51}$.

Las causas civiles han sido tipificadas a partir de 5 variables que hacen referencia al asunto o proceso que refieren: deudas, familia, indígenas, institucional y venta de solares. Las deudas podían ser por entregas incumplidas, cartas de obligación concedidas o remate de derechos de alcabalas. En los casos de familias incluimos los conflictos por testamentarías que afectaban a menores, albaceas o a hijos ilegítimos. Las causas referidas a indígenas presentaban distinta naturaleza. Entre los documentos judicializados encontramos documentación que corresponde a visitas de indios, nombramiento de corregidores, relaciones de indios abipones, pedidos de indios mitayos, que no siempre constituían pleitos judiciales.

\begin{tabular}{|c|c|}
\hline \multicolumn{2}{|c|}{ CLASIFICACIÓN DE CAUSAS CIVILES } \\
\hline Variables & Cantidad de causas \\
\hline Deudas & 28 \\
\hline Indígenas & 27 \\
\hline Familia & 12 \\
\hline Venta de solares & 7 \\
\hline
\end{tabular}

Fig. 1: Clasificación de causas civiles. Fuente: Elaboración propia a partir de AGPC. Sala I. Judiciales. Tomo I-VI.

\section{b) Las causas criminales}

"El sargento mayor Bernardo de Centurion vecino encomendero en aquel grado que convenga y digo que sea servido de darme lista de autos y sumaria información que ante su vuestra merced sobre la muerte de un indio Antonio que pretenden acumular a una india de mi encomienda llamada Antonia del pueblo y la reducción de Nuestra Señora de Itatí ${ }^{\prime 62}$... así iniciaba el litigio criminal que se producía a causa de la muerte de Antonio perteneciente a la encomienda de Blas Cobos de Arce. Este

51 POCZYYNOK, Cristian Miguel. La propiedad de la tierra como un "haz de derechos". Una contribución desde la campaña bonaerense en un momento de transición. Mundo agrario. 2018, vol. 19, n. 41, p. 2. Ver: CONGOST, Rosa. Tierras, leyes, historia. Estudios sobre "la gran obra de la propiedad". Barcelona: Crítica, 2007; GARAVAGLIA, Juan Carlos. Pastores y labradores de Buenos Aires. Buenos Aires: Ed. de la Flor, 1999.

${ }^{52}$ AGPC. Sala I. Judiciales. Tomo 3. Foja 83-120v. 
caso que afectaba a un indio encomendado no era el único que aparecía en las actas judiciales, años antes, encontrábamos que había recibido malos tratamientos la india Antonia Rea de la parcialidad hometa de la encomienda de Juan de Salinas y, poco tiempo después, iniciaba un litigio a raíz de los malos tratamientos dado a los indios "jubilados" de la nación opiosna en el cual, el indio Martin había sido herido y descalabrado ${ }^{53}$. Este conjunto de causas criminales eran las más frecuentes que se exponían en los expedientes judiciales, en principio, nos lleva a preguntarnos qué entendemos por delito en la época estudiada.

El delito hace referencia a un conjunto de conductas que tuvieron en común el hecho de encontrarse proscriptas por la ley criminal colonial o post-colonial. Las leyes castellanas que codificaron apartados penales fueron las Siete Partidas de Alfonso X, la Recopilación de Leyes de Indias y la Novísima Recopilación de 1806, sumado a los numerosos bandos de buen gobierno que regulaban la vida local de los vecinos y habitantes de la ciudad.

Las causas criminales implicaban que una persona física fuese afectada a raíz de algún ataque, lesión, injuria, etc.; dentro de las mismas podrían incluirse acciones que afectaban los derechos de propiedad (como robos o hurtos) o a su propia integridad física. La persona podía perder su vida o recibir una lesión, así surgía el delito de homicidio y el de injurias de hechos. El homicidio era un cosa que hacen los hombres a veces de manera injusta y a veces con derecho según las Partidas de Alfonso $X$ el Sabio. El acto de dar muerte a otra persona se puede dar por tres razones: "el cometido contra derecho o razón y a sabidas del crimen realizado, el ocurrido en defensa propia 0 el perpetrado de manera involuntaria o por accidente" $"$. Los delitos de injurias de hecho eran las heridas o lesiones personales que se realizaban pero que no ocasionaban la muerte de la víctima, podían ser golpes, golpizas, puñaladas, azotes, lesiones, peleas, entre otras. En las causas exploradas del siglo XVII, la mayoría de los delitos constituían injurias de hecho ${ }^{55}$ y solo aparecía una muerte de una persona. En las injurias, los individuos afectados reciben heridas, lesiones o agresiones físicas.

El número de causas criminales, en relación a las civiles, son escasas en este período temprano. Creemos que, quizás, no era frecuente hacer uso de la justicia para solucionar estos tipos de conflictos que se generaban en la cotidianeidad. Es sumamente interesante, observar que no se da ningún proceso criminal vinculado a la toma de alguna cosa sin licencia y voluntad de su dueño, sino que las pocas causas afectan a las personas.

La cuestión de identificar causas criminales vinculadas a la persona nos lleva a considerar definiciones que han sido problematizadas para sociedades preindustriales del antiguo régimen. En esos espacios, se preguntaban "si en sociedades europeas han evolucionado las formas de crimen desde el predominio

\footnotetext{
${ }^{53}$ AGPC. Sala I. Judiciales. Tomo 3. Foja 9-41v.

${ }^{54}$ Alfonso X. Las siete partidas. Partidas X. Título 8 [en línea]. Disponible en $<$ https://www.biblioteca.org.ar/libros/130949.pdf>.

${ }_{55}$ Dos de ellas, están en un muy mal estado de conservación. Solo podemos reconstruir algunas palabras del documento.
} 
de los crímenes contra las personas y desde las violencias interpersonales hasta el predominio de los delitos contra la propiedad, a medida que se fue definiendo e identificando mejor en los textos jurídicos" $" 56$.

\subsection{Las autoridades intervinientes en los litigios del siglo XVII}

En las causas judicializadas encontramos que intervenían dos autoridades: los alcaldes de primer y segundo voto y los tenientes de gobernador.

Los alcaldes de primer y segundo voto, que se aparecen en el cuadro $\mathrm{N}^{\circ} 2$, actuaron en las causas civiles vinculadas a conflictos de testamentarias, las deudas, litigios por venta de solares y en una causa vinculada a una venta del oficio de regidor. Dado que "la competencia de los alcaldes se extendía a todas las causas civiles y criminales, cualquiera fuese su importancia, pero no podían inmiscuirse en las materias de gobierno ni en los asuntos correspondientes a algún fuero 0 privilegio. Los alcaldes entendían los pleitos entre españoles y también en parte en los que fuese parte un indio" 57 .

\begin{tabular}{|c|c|}
\hline \multicolumn{2}{|c|}{ ALCALDES QUE INTERVINIERON EN CAUSAS JUDICIALIZADAS ENTRE 1612-1680 } \\
\hline Alcaldes & Cantidad de casos que intervinieron \\
\hline Lázaro de Almirón & 1 \\
\hline Marcos Gómez Durán & 1 \\
\hline Gabriel de Insaurralde & 1 \\
\hline Manuel de Cabrera & 1 \\
\hline Diego Rodríguez & 2 \\
\hline Martín de Villanueva & 1 \\
\hline Pedro Gómez de Aguiar & 2 \\
\hline Juan Díaz de Almirón & 2 \\
\hline Gabriel López de Arriola & 2 \\
\hline Juan Díaz Moreno & 1 \\
\hline Antón de Don Benito & 1 \\
\hline Pedro Gómez de Mesa & 1 \\
\hline Víctor Figueroa & 1 \\
\hline Blas Arias & 1 \\
\hline Díaz Rodríguez & 1 \\
\hline Felipe Díaz de Agüero & 1 \\
\hline Antonio de Soto & 1 \\
\hline
\end{tabular}

Fig. 2: Alcaldes que intervinieron en causas judicializadas entre 1612-1680. Fuente: Elaboración propia a partir de AGPC. Judiciales. Sala I-VI.

La actuación de los tenientes de gobernador en virtud de su condición de justicia mayor se orientó a litigios civiles y criminales. No todas las causas que encontrábamos son de apelación, la mayoría da cuenta que estos funcionarios oían justicia en primera instancia en el espacio de la ciudad de Corrientes. Nos interesa enfatizar que las causas que involucraban a los indígenas eran llevadas y desarrolladas por el teniente de gobernador.

\footnotetext{
${ }^{56}$ MANTECON, Tomás. El peso de la infrajudicialidad en el control del crimen durante la edad moderna. Estudis. 2002, n. 28, p. 48.

57 ZORRAQUíN BECÚ, Ricardo. La organización judicial argentina en el período hispánico. Buenos Aires: Ed. Perrot, 1981, p. 55.
} 


\begin{tabular}{|} 
TENIENTES DE GOBERNANDOR QUE INTERVINIERON EN CAUSAS JUDICIALIZADAS ENTRE \\
\begin{tabular}{|c|c|}
\hline Teniente de gobernador & № de casos actuados \\
\hline Juan de Saavedra & 1 \\
\hline Roque de Mendieta & 4 \\
\hline Miguel de Biegol y Velasco & 2 \\
\hline Pedro Gómez de Aguiar & 4 \\
\hline Sebastián Crespo Flores & 6 \\
\hline Nicolás Pessoa de Figueroa & 1 \\
\hline Francisco de Villanueba & 4 \\
\hline Alonso Delgadillo y Atienza & 6 \\
\hline Ambrosio de Acosta & 2 \\
\hline
\end{tabular}
\end{tabular}

Fig. 3: Tenientes de gobernador que intervinieron en causas judicializadas entre 1612-1680. Fuente: Elaboración propia a partir de AGPC. Judiciales. Sala I-VI.

Por fuera de los tenientes de gobernador y de los alcaldes, es interesante observar la actuación de los protectores de naturales que se constituyen como el magistrado que representa a los indígenas en los proceso judicializados. La presencia de este magistrado manifiesta los cambios acontecidos por la puesta en funcionamiento de las ordenanzas toledanas, que crea el cargo del protector general de indios para aglutinar los reclamos indígenas y dinamizar la litigiosidad indígena. Es clave observar que este funcionario tiende a poner en evidencia los incumplimientos que se dan en relación al trabajo indígena ${ }^{58}$.

Entre las causas que llegaron a los tribunales superiores, encontramos registros de actuaciones del gobernador de Buenos Aires como el caso de Pedro de Baygorria. La causa trataba sobre el vagabundeo de los indios en la jurisdicción que no cumplían con la obligación de la mita, la cual fue resuelta en el tribunal superior por el gobernador en calidad de sus atribuciones de juez real.

Así también, en los expedientes que tratan sobre las visitas de indios que hallamos en el fondo judicial, también actúan otros gobernadores de Buenos Aires, como Joseph Martínez de Zalazar.

Por último, es necesario señalar que existen causas en donde los corregidores de indios adquieren relevancia, dado que en algunos litigios fueron acusados de incumplir en el tratamiento indígena.

\section{Discursos y experiencias de la temprana sociedad colonial correntina a partir de los pleitos judiciales}

La ciudad de Corrientes o San Juan de Vera, como se la denominan en los documentos, fue fundada en 1588. Los primeros años de asentamiento implicaron la distribución de la tierra, el sometimiento y encomienda de los indios, así como la organización económica de la ciudad ${ }^{59}$. A unas 20 leguas del ejido urbano se repartieron tierras para chacras y estancias para el ganado. Asimismo, se efectuaron

\footnotetext{
${ }^{58}$ Creemos que esta cuestión debe ser analizado con mayor profundidad en otros trabajos centrados en la población indígena y su acceso a la justicia.

${ }^{59}$ MAEDER, Ernesto. Historia económica de Corrientes... Op. cit., p. 20.
} 
repartos de indios en encomiendas en 1588, 1589, 1590, 1592, 1593 y 1598. Años después se organizaron la radicación de algunas parcialidades aborígenes en reducciones y poblados ${ }^{60}$, como Itatí, Santa Lucía de los Astos y San Francisco bajo la doctrina de los franciscanos ${ }^{61}$.

Para 1620, el gobernador Diego de Góngora señalaba que habitaban en la ciudad: "unos 40 vecinos españoles, en unas barrancas, (...) en donde servían los indios de nación guaraní... que parte de ellos están en paz, y los más de guerra (...) tienen buenas tierras y mucha cantidad de ganados vacuno cimarrón. Es la tierra fértil..."62.

Los litigios judiciales corroboran esa configuración social, económica y política de la incipiente ciudad de San Juan de Vera, sobre todo de las bases del sistema económico y las formas laborales vinculadas a la encomienda indígena.

La ganadería era la principal fuente de recursos de los primeros tiempos. En torno a esta situación, aparecen y se acumulan pleitos vinculados al arreo, guarda y obligaciones de ganado entre particulares. Por ejemplo, en 1671 tomamos el caso de "la denuncia que se le hace al capitán Pedro de Moreyra, alcalde de Santa Hermandad, por ser deudor de unas doscientas veinticuatro cabezas de ganado vacuno puestas en la ciudad de Asunción"63. Este, como tantos otros litigios, arroja pistas de las relaciones económicas entabladas por los particulares correntinos con vecinos de Asunción, Santa Fe o Buenos Aires.

Las causas relacionadas con la ganadería, también, reflejan aspectos vinculados al dominio y ocupación de las tierras correntinas, pero sobre todo al aprovechamiento del ganado por medio del régimen de las vaquerías ${ }^{64}$. En 1661 , encontramos un pleito que se suscita por la vaquería realizada por los indios de los pueblos de Itatí, Santa Lucía y Santiago Sánchez. El ganado se dispersaba y circulaba por diferentes espacios como la banda del río Paraná, el río Santa Lucía y el río Corrientes.

En ese sentido, la sociedad correntina del siglo XVII se representa como una pequeña comunidad económica que desarrolla lazos comerciales con ciudades y espacios cercanos. Los litigios reflejan las redes comerciales que generaban vecinos correntinos con residentes en Asunción y Santa Fe. Así se prometían ganados y carretas unos a otros, que muchas veces se incumplían.

La otra cuestión que manifiestan estos primeros casos judiciales del siglo XVII refiere al trabajo indígena o a la posesión de estos en encomiendas. Así se dan dos

\footnotetext{
${ }^{60}$ Ver: SALINAS, María Laura. Dominación colonial y trabajo indígena. Un estudio de la encomienda de Corrientes colonial. Centro de Estudios Antropológicos de la Universidad Católica (CEADUC), Biblioteca de Estudios Paraguayos. May. 2010, vol. 81.

${ }^{61}$ Ibídem, p. 21.

62 Relación de Diego de Góngora, 1622 en MAEDER, Ernesto. Historia económica de Corrientes... Op. cit., p. 25.

${ }^{63}$ AGPC. Judiciales. Tomo 6. Foja 214. Año 1672.

${ }^{64}$ Para el tema de las vaquerías resultan interesantes los abordajes de MAEDER, Ernesto (1981) para el caso correntino; en tanto otro aporte significativo es BARRIERA, Darío (2019).
} 
tipos de litigios: la cuestión de las encomiendas vacas que produce conflicto entre los encomenderos o sus sucesores y las otras causas, en donde el protector de naturales presenta cargos contra los encomenderos y/o corregidores por ciertos abusos o incumplimiento en los sistemas laborales.

El trabajo indígena es un experiencia central de la sociedad correntina en el siglo $\mathrm{XVII}$, con lo cual, los pleitos exteriorizan las relaciones entre encomenderos y encomendados. Pero también evocan mediaciones y regulaciones en donde otros actores juegan un rol central como el protector de naturales, los alcaldes, funcionarios reales, entre otros.

En un plano más íntimo, las causas civiles manifiestan cuestiones particulares referidas a la vida de los vecinos y residentes de San Juan de Vera. En ese universo, adquieren significancia tanto las testamentarias, como las concesiones de bienes, la legitimación de los hijos naturales y/o nombramiento de tutores de menores.

\section{Algunas conclusiones finales}

A lo largo del artículo, presentamos una tensión latente en la formulación y elaboración de instrumentos descriptivos, como una tarea prioritaria de los archivistas. No obstante, observamos ejemplos en los cuales fue el historiador quien asumió el trabajo en ese universo heurístico. En ese escenario, ubicábamos nuestro accionar en el Archivo General de la Provincia de Corrientes y, más puntualmente, en el fondo judicial.

Por una multiplicidad de necesidad y urgencias archivistas e históricas, surgió la elaboración de un catálogo pormenorizado de cada una de las unidades documentales compuestas que fuimos encontrando en el fondo judicial correntino. Ese catálogo lo construimos en torno a una serie de variables: año de producción de la causa, materia de la causa: civil-criminal, asunto o esencia dela pleito, nombre del litigante, nombre del demandante y autoridades intervinientes. Creemos que este catálogo es fundamental para poder adentrarnos en una lectura en torno funcionamiento de la cultura jurídica en Corrientes, y sobre todo, a la configuración social, económica y política de la incipiente sociedad de San Juan de Vera.

En esta oportunidad, el catálogo se ajusta a una primera etapa del siglo XVII, pero se vuelve necesario extender la elaboración de este instrumento con la totalidad de las fuentes judiciales del período. Con lo cual, las conclusiones observadas podrían ser comprobadas o refutadas con mayor rigurosidad con el procesamiento total del fondo.

Los casos explorados se localizaron entre los tomos 1 al 6 correspondientes al período 1612 y 1680, estos nos permitieron dar cuenta de los conflictos que protagonizaban los vecinos y residentes en San Juan de Vera. A su vez, también, observamos la actuación de los funcionarios que defendían intereses de sectores desprotegidos como los protectores de naturales que se presentaban en defensa de los indios originarios y mitayos. Así las causas nos fueron presentando problemas 
sobre la vida cotidiana como era el trabajo indígena y sobre todo, constantes litigios económicos que se generaban entre vecinos dedicados a las vaquerías. Sin olvidar conflictos particulares en relación a testamentarias y concesiones de bienes, esos eran algunos de los casos que se suscitaban en la temprana sociedad colonial correntina ante la justicia de primera instancia. De esa manera los expedientes judiciales exteriorizan una suma de causas que se posicionan en el terreno civil y criminal

Consideramos que esta primera exploración revela el enorme y valioso valor histórico y archivístico de este trabajo. Pues un catálogo organizado y pormenorizado permitirá que el historiador pueda producir conocimiento en torno a las experiencias y discursos que arrojan las fuentes judiciales.

\section{Fuentes}

Archivo General de la Provincia de Corrientes (AGPC).

Sala I. Judiciales

Tomo 1. Período: 1619-1658

Tomo 2. Período: $1658-1660$

Tomo 3. Período: 1660-1664.

Tomo 4. Período: $1664-1666$

Tomo 5. Período: 1666-1670.

Tomo 6. Período: 1670-1672.

\section{Bibliografía}

Alfonso $\mathrm{X}$. Las siete partidas [en línea]. Disponible en $<$ https://www.biblioteca.org.ar/libros/130949.pdf>.

BARRIERA, Darío. Justicias, jueces y culturas jurídicas en el siglo XIX rioplatense. Nuevo Mundo Mundos Nuevos. 2010.

BARRIERA, Darío. La ciudad y las varas: justicia, justicias y jurisdicciones. Siglo XVI-XVII. Revista de Historia del Derecho. 2003, n. 31, pp. 75-76.

BARRIERA, Darío. Justicias rurales: el oficio de alcalde de la hermandad entre el derecho, la historia y la historiografía (Santa Fe, Gobernación del Río de la Plata, siglos XVII a XIX). Andes, 2013.

BARRIERA, Darío, Instituciones, justicias de proximidad y derecho local en un contexto reformista. Revista de Historia del Derecho Sección Investigaciones. Jul./Dic. 2012, n. 44, pp. 1-28.

BARRIERA, Darío. Abrir las puertas de la tierra. Microanálisis de la construcción de un espacio político. Santa Fe, 1573-1640. $2^{\circ}$ ed. Santa Fe: Ministerio de Innovación y Cultura de la Provincia de Santa Fe; Museo histórico provincial, 2017.

BARRIERA, Darío. Historia y justicia. Cultura, política y sociedad en el Río de la 
Plata (Siglos XVI-XIX). Buenos Aires: Prometeo Libros, 2019.

CONGOST, Rosa. Tierras, leyes, historia. Estudios sobre "la gran obra de la propiedad". Barcelona: Crítica, 2007.

CORVA, Angélica. Rastreando huellas. La búsqueda de documentos judiciales para la investigación histórica. Revista Electrónica de Fuentes y Archivos. 2015, n. 6, pp. 43-65.

CRUZ MUNDET, José Ramón. Manual de archivística. Madrid: Pirámide, 1994.

DEPETRIS, Nicolás. Visiones del pasado: la Nueva Escuela Histórica y los positivistas. Sociales y Virtuales. 2019, vol. 6, n. 6.

FARGE, Arlette. La atracción del archivo. Institucio Valenciana D’Estudis i Investigacio; Edicicions Alfons El Magnanim, 1991.

HEREDIA HERRERA, Antonia. Archivística general. Teoría y práctica. 5o ed. actualizada. Sevilla: Servicios de publicaciones de la Diputación, 1991, p. 143.

LEONI, María Silvia y QUIÑÓNEZ, María Gabriela, Debates y polémicas en la conformación del campo historiográfico correntino a fines del siglo XIX. Anuario del Instituto de Historia Argentina. 2015, n. 15, p. 2.

GARAVAGLIA, Juan Carlos. Pastores y labradores de Buenos Aires. Buenos Aires: Ed. de la Flor, 1999.

LEVAGGI, Abelardo. Manual de Historia del derecho argentino. Tomo II. Buenos Aires: LexisNexis, 2005.

MAEDER, Ernesto. Relevamiento de los fondos documentales de los archivos de la región Nordeste Argentina y de Asunción del Paraguay. Revista de Estudios Regionales. 1978, pp. 7-61.

MAEDER, Ernesto. Historia económica de Corrientes en el periodo virreinal. 17761810. Buenos Aires: Academia Nacional de la Historia, 1981.

MANTECON, Tomás. El peso de la infrajudicialidad en el control del crimen durante la edad moderna. Estudis. 2002, n. 28, p. 48.

MOLINA, Eugenia. Tras los pasos de la justicia. Algunos aportes de la historiografía de la justicia para el Río de la Plata tardocolonial y republicano temprano en relación con los procesos de estatalidad. PolHIS. Jul./Dic. 2015, año 8, n. 16, pp. 126-157.

OLGUÍN FERNÁNDEZ, Eduardo. Los archivos de la ciudad de Corrientes. Buenos Aires. Publicaciones de la Sección de Historia. Facultad de Filosofía y Letras. 1921, n. VIII. 
PAGÁN, Ester Alba. Catálogo e inventario como instrumentos para la gestión del patrimonio cultural. En: Jornada "Educació $i$ formació en torn al patrimoni cultural de l'interior". Xàtiva, 11 de diciembre de 2013.

PALMA, Federico. Archivos correntinos. Corrientes: Universidad Nacional del Nordeste, 1967, p. 9.

POCZYYNOK, Cristian Miguel. La propiedad de la tierra como un "haz de derechos". Una contribución desde la campaña bonaerense en un momento de transición. Mundo agrario. 2018, vol. 19, n. 41, p. 2.

POZZAGLIO, Fernando Ariel; MORENO CABANILLAS Rocío y SVRIZ WUCHERER, Pedro Miguel Omar. Fuentes y tipos documentales para reconstruir la historia de la ciudad de Corrientes durante la época colonial. REFA. Revista Electrónica de Fuentes y Archivos. 2018, año 9, n. 9, pp. 97-117.

POZZAGLIO, Fernando. El cabildo y la elite en Corrientes, desde la fundación hasta 1782 [tesis doctoral]. Buenos Aires: Universidad del Salvador, 2015.

PUSINERI, Adelina. Estado de las fuentes documentales y bibliotecas públicas y privadas en el Paraguay para el estudio de las dos guerras. Nuevo Mundo Mundos Nuevos [en línea]. 2006. Disponible en $<$ http://journals.openedition.org/nuevomundo/2187>.

SALINAS, María Laura. Dominación colonial y trabajo indígena. Un estudio de la encomienda de Corrientes colonial. Centro de Estudios Antropológicos de la Universidad Católica (CEADUC), Biblioteca de Estudios Paraguayos. May. 2010, vol. 81.

SALINAS, María Laura y VALENZUELA, Fátima. Fondos judiciales y Humanidades digitales en espacio periféricos del Imperio español. El Archivo General de la provincia de Corrientes, Argentina. Siglos XVII-XIX. Temas Americanistas. Jun. 2019, n. 42, pp. 138-159.

SCHALLER, Enrique César. Fuentes para el estudio de la economía, sociedad y organización estatal en el nordeste argentino en la etapa colonial e independiente. La documentación del Archivo de la Provincia de Corrientes. REFA. Revista Electrónica de Fuentes y Archivos. 2019, año 10, n. 10.

SOLIS CARNICER, María del Mar. Entre la tradición y la renovación historiográfica. Federico Palma y su contribución a la historiografía correntina contemporánea. En: MAEDER, Ernesto; LEONI, M. Silvia y QUINONEZ, M. Gabriela. Visiones del Pasado. Estudios de Historiografía de Corrientes. Corrientes: Moglia, 2004, pp. 109-157.

TELESCA, Ignacio. Documentos jesuíticos del siglo XVIII en el Archivo Nacional de Asunción. Asunción: Centro de estudios paraguayos, 2006.

TUTTE, Andrea. Catálogo de la Sección Historia del Archivo Nacional. Asunción: 
Tiempo de Historia, 2008.

\section{ZORRAQUÍN BECÚ, Ricardo. La organización judicial argentina en el período hispánico. Buenos Aires: Ed. Perrot, 1981.}

\section{Anexo}

\begin{tabular}{|c|c|c|c|c|c|c|}
\hline \multicolumn{7}{|c|}{ Catálogo de causas judicializadas } \\
\hline $\mathbf{N}^{\circ}$ & Año & Materia & Motivo & $\begin{array}{l}\text { Litigante } \\
\end{array}$ & Demandante & $\begin{array}{c}\text { Autoridad } \\
\text { interviniente }\end{array}$ \\
\hline 1 & $\begin{array}{l}1647- \\
1651\end{array}$ & Civil & $\begin{array}{l}\text { Inventario de bienes de } \\
\text { Juan Serrudo }\end{array}$ & $\begin{array}{c}\text { Juan Lescano, tutor de } \\
\text { los hijos }\end{array}$ & $\begin{array}{c}\text { Albaceas y } \\
\text { tenedores de } \\
\text { bienes: Gerónimo } \\
\text { Martínez, Isidro } \\
\text { Ballejos y Lazaro } \\
\text { Serrudo }\end{array}$ & $\begin{array}{l}\text { Lázaro de Almirón, } \\
\text { alcalde ordinario }\end{array}$ \\
\hline 2 & ----- & Civil & $\begin{array}{c}\text { Nombramiento de tutor e } \\
\text { inventario de bienes de } \\
\text { María Ballejos }\end{array}$ & Francisco de Alcaraz & ----- & $\begin{array}{l}\text { Marcos Gómez } \\
\text { Duran alcalde } \\
\text { ordinario }\end{array}$ \\
\hline 3 & 1625 & Criminal & $\begin{array}{l}\text { Intento de asesinato- } \\
\text { prisión }\end{array}$ & Bartolomé de Burgos & Felipa de Almada & $\begin{array}{c}\text { Gabriel de } \\
\text { Insaurralde, alcalde } \\
\text { ordinario }\end{array}$ \\
\hline 4 & 1653 & Civil & Mal tratamiento a indios & $\begin{array}{c}\text { Gabriel López de } \\
\text { Arriola protector de } \\
\text { naturales en nombre } \\
\text { de Martin indio de la } \\
\text { encomienda de nación } \\
\text { opiosna }\end{array}$ & Antonio de Miranda & $\begin{array}{c}\text { Capitán Juan de } \\
\text { Saavedra, capitán a } \\
\text { guerra }\end{array}$ \\
\hline 5 & 1657 & Civil & $\begin{array}{l}\text { Deuda de unos caballos y } \\
\text { carreta }\end{array}$ & Juan de Saavedra & $\begin{array}{c}\text { Ambrosio de } \\
\text { Acosta }\end{array}$ & $\begin{array}{l}\text { Causa de apelación } \\
\text { y nulidad llevada } \\
\text { adelante por el } \\
\text { acalde ordinario } \\
\text { Manuel de Cabrera }\end{array}$ \\
\hline 6 & 1658 & Civil & $\begin{array}{c}\text { Encomienda vaca de indios } \\
\text { mahomas que Santiago } \\
\text { Sánchez que pertenecía a } \\
\text { Juan Gómez }\end{array}$ & $\begin{array}{c}\text { López de Arriola } \\
\text { protector general de } \\
\text { naturales en nombre } \\
\text { de Macho cacique } \\
\text { principal de la nación } \\
\text { maho } \\
\end{array}$ & ------ & $\begin{array}{c}\text { Teniente de } \\
\text { gobernador Roque } \\
\text { de Mendieta }\end{array}$ \\
\hline 7 & --- & Civil & $\begin{array}{c}\text { Tasación y partición de } \\
\text { bienes de María de } \\
\text { Sandoval }\end{array}$ & Alonso Montiel & ------ & Roque de Mendieta \\
\hline 8 & 1620 & Civil & Conflicto por encomienda & $\begin{array}{c}\text { Andres Maciel, en } \\
\text { nombre de su esposa } \\
\text { Magdalena Cuevba }\end{array}$ & Juan Almirón & $\begin{array}{c}\text { Miguel de Biegol y } \\
\text { Velasco, justicia } \\
\text { mayor y capitán a } \\
\text { guerra }\end{array}$ \\
\hline 9 & 1659 & Civil & $\begin{array}{l}\text { Remate derecho de } \\
\text { alcabala }\end{array}$ & Francisco de Aguero & $\begin{array}{c}\text { Diego de Jiménez } \\
\text { de Medina }\end{array}$ & $\begin{array}{c}\text { Teniente de } \\
\text { gobernador, Roque } \\
\text { de Mendieta }\end{array}$ \\
\hline 10 & 1659 & Civil & Litigio por encomienda & $\begin{array}{l}\text { Juan González de } \\
\text { Santa Cruz }\end{array}$ & Juana de Acuña & $\begin{array}{c}\text { Roque de } \\
\text { Mendieta, teniente } \\
\text { de gobernador }\end{array}$ \\
\hline 11 & 1660 & Civil & $\begin{array}{l}\text { Pedido de administración } \\
\text { de encomienda }\end{array}$ & $\begin{array}{l}\text { Pedro Gomez de } \\
\text { Aguiar en nombre de } \\
\text { Petronila de Garnica } \\
\end{array}$ & ----- & $\begin{array}{c}\text { Roque de } \\
\text { Mendieta, teniente } \\
\text { de gobernador } \\
\end{array}$ \\
\hline 12 & 1660 & Civil & $\begin{array}{c}\text { Pago de deudas por } \\
\text { diezmos }\end{array}$ & Diego de Ortega & Gabriel de Esquivel & $\begin{array}{l}\text { Diego Rodríguez, } \\
\text { alcalde ordinario }\end{array}$ \\
\hline 13 & 1660 & Criminal & $\begin{array}{c}\text { Malos tratamientos a } \\
\text { muchachos y muchachas } \\
\text { de la encomienda de Juan } \\
\text { de Salinas }\end{array}$ & $\begin{array}{c}\text { Gabriel de Lopez, } \\
\text { protector de naturales }\end{array}$ & Antonio de Miranda & Roque de Mendieta \\
\hline 14 & 1659 & Civil & Pedido de un indio & Mateo Cardozo & $\begin{array}{l}\text { Doña Mariana } \\
\text { Álvarez Gaitán }\end{array}$ & Roque de Mendieta \\
\hline 15 & 1660 & Civil & Encomienda & Melchor Cardozo & Baltazar Flores & Roque de Mendieta \\
\hline 16 & 1659 & Civil & Litigio por una casa & Atanacio de Sosa & $\begin{array}{l}\text { Lorenzo de Avila, } \\
\text { yerno de Ana } \\
\text { Fernandez }\end{array}$ & $\begin{array}{l}\text { Diego Rodríguez, } \\
\text { alcalde ordinario }\end{array}$ \\
\hline 17 & 1660 & Civil & Pedido de pago de & Manuel Baes & ------- & Cabildo de Santa \\
\hline
\end{tabular}


Fátima VALENZUELA y Fernando POZZAGLIO. Redescubrimiento de los pleitos judiciales de una temprana sociedad colonial. Corrientes, Río de la Plata (1588-1680).

\begin{tabular}{|c|c|c|c|c|c|c|}
\hline & & & aguardiente & & & $\mathrm{Fe}$ \\
\hline 18 & 1661 & Criminal & $\begin{array}{l}\text { Muerte de un indio de la } \\
\text { encomienda de Blas } \\
\text { Cobos, Antonio }\end{array}$ & $\begin{array}{c}\text { Sargento Mayor } \\
\text { Bernardo de Centurion }\end{array}$ & $\begin{array}{l}\text { Antonia del pueblo } \\
\text { y reducción de Itatí }\end{array}$ & $\begin{array}{c}\text { Martín de } \\
\text { Villanueba, alcalde } \\
\text { ordinario }\end{array}$ \\
\hline 19 & 1650 & Civil & $\begin{array}{c}\text { Cobro de bienes } \\
-400 \text { pesos en tabaco- }\end{array}$ & Juan de Orellano & Pedro de Obelar & $\begin{array}{l}\text { Pedro Gomez de } \\
\text { Aguiar, alcalde } \\
\text { ordinario }\end{array}$ \\
\hline 20 & 1661 & Civil & $\begin{array}{l}\text { Restituir oficios vendibles y } \\
\text { renunciables }\end{array}$ & Marcos Gomez Duran & ------ & $\begin{array}{l}\text { Roque de Zarate- } \\
\text { Garabito de León }\end{array}$ \\
\hline 21 & 1661 & Criminal & $\begin{array}{l}\text { Maltrato a indios jubilados } \\
\text { de la nación opiosna }\end{array}$ & $\begin{array}{l}\text { El capitán Gabriel de } \\
\text { Arriola, protector de } \\
\text { naturales en nombre } \\
\text { de Martin Crespo } \\
\text { Flores }\end{array}$ & Antonio de Miranda & $\begin{array}{l}\text { Alonso Mercado } \\
\text { Villacorta, } \\
\text { gobernador de } \\
\text { Buenos Aires ha } \\
\text { visto la querella } \\
\text { criminal }\end{array}$ \\
\hline 22 & 1665 & Civil & $\begin{array}{c}\text { Demanda por el medio } \\
\text { solar }\end{array}$ & $\begin{array}{l}\text { María y Catalina } \\
\text { Rodríguez }\end{array}$ & $\begin{array}{l}------ \\
\end{array}$ & $\begin{array}{l}\text { Alcalde capitán } \\
\text { Juan de Almirón }\end{array}$ \\
\hline 23 & 1665 & Civil & $\begin{array}{l}\text { Restitución de indio } \\
\text { Ilamado Juan de nación } \\
\text { nagasti }\end{array}$ & $\begin{array}{l}\text { Protector de Naturales, } \\
\text { Juan de Salinas }\end{array}$ & $\begin{array}{l}\text { Doña Magdalena } \\
\text { de Cuevas }\end{array}$ & $\begin{array}{l}\text { Pedro Gomez de } \\
\text { Aguiar, corregidor y } \\
\text { lugarteniente }\end{array}$ \\
\hline 24 & 1660 & Civil & $\begin{array}{l}\text { Defensa por exceso en el } \\
\text { trabajo laboral establecido } \\
\text { por ordenanza }\end{array}$ & Luis de Burgos & $\begin{array}{l}\text { Manuel Cabral de } \\
\text { Alpoin }\end{array}$ & Roque de Mendieta \\
\hline 25 & 1664 & Civil & $\begin{array}{c}\text { Demanda por géneros de } \\
\text { mercaderías }\end{array}$ & $\begin{array}{l}\text { Pedro Rodríguez de } \\
\text { Gama }\end{array}$ & Juana de Maidana & $\begin{array}{l}\text { Capitán Gabriel } \\
\text { López de Arriola, } \\
\text { alcalde ordinario }\end{array}$ \\
\hline 26 & 1668 & Civil & $\begin{array}{c}\text { Relación de como los } \\
\text { indios enemigos de nación } \\
\text { abipones dieron una } \\
\text { noche... }\end{array}$ & Gabriel de Toledo & $\begin{array}{l}----- \\
\end{array}$ & $\begin{array}{l}\text { Teniente de } \\
\text { gobernador }\end{array}$ \\
\hline 27 & 1670 & Civil & Testamentaria & $\begin{array}{l}\text { Don Melchor Aranda y } \\
\text { su mujer doña Lorenza } \\
\text { Flora }\end{array}$ & $\begin{array}{l}\text { Defensor de } \\
\text { menores, Juan } \\
\text { Benítez }\end{array}$ & $\begin{array}{c}\text { Teniente de } \\
\text { gobernador, justicia } \\
\text { mayor y capitán a } \\
\text { guerra }\end{array}$ \\
\hline 28 & & Civil & Deuda de varios meses & $\begin{array}{l}\text { Alferez Vargas } \\
\text { Machuca }\end{array}$ & $\begin{array}{l}\text { Cristobal Cabral de } \\
\text { Melo-Cristobal } \\
\text { Baldez Villaboas }\end{array}$ & \\
\hline 29 & 1654 & Civil & $\begin{array}{c}\text { Alquiler de una carreta por } \\
\text { ropa }\end{array}$ & $\begin{array}{c}\text { Pedro Rodríguez de } \\
\text { Gama }\end{array}$ & $\begin{array}{r}\text { doña Juana de } \\
\text { Maydana viuda }\end{array}$ & $\begin{array}{c}\text { Lopez de Arriola, } \\
\text { alcalde }\end{array}$ \\
\hline 30 & 1665 & civil & $\begin{array}{l}\text { Real ordenanza para que } \\
\text { haya corregidores en los } \\
\text { pueblos / Petición del } \\
\text { procurador de esta ciudad } \\
\text { para que haya corregidores } \\
\text { y administradores }\end{array}$ & Encomienda & ----- & $\begin{array}{l}\text { Sebastian Crespo } \\
\text { Flores, teniente }\end{array}$ \\
\hline 31 & 1663 & civil & $\begin{array}{c}\text { Estado de cuenta de } \\
\text { cincuenta y un indios } \\
\text { mitayos del pueblo de } \\
\text { ohoma / deuda y embargo/ } \\
\text { nulidad de encomienda }\end{array}$ & Encomienda & $\begin{array}{l}----- \\
\end{array}$ & $\begin{array}{l}\text { Pedro Gomez de } \\
\text { Aguiar, corregidor, } \\
\text { lugarteniente de } \\
\text { gobernador }\end{array}$ \\
\hline 32 & 1664 & Civil & $\begin{array}{l}\text { Vendió a la india a por unas } \\
\text { palmas y otros géneros }\end{array}$ & ---- & Alonso Montenegro & $\begin{array}{l}\text { Pedro Gomez de } \\
\text { Aguiar, corregidor, } \\
\text { lugarteniente de } \\
\text { gobernador }\end{array}$ \\
\hline 33 & & Civil & Remate de cargos & Oficio de regidor & ----- & $\begin{array}{l}\text { Juan Diaz Moreno, } \\
\text { alcalde }\end{array}$ \\
\hline 34 & 1664 & Civil & $\begin{array}{c}\text { Deuda por caballos y de } \\
\text { otras cosas }\end{array}$ & Salbador Fernandez & $\begin{array}{l}\text { Agustín Básquez } \\
\text { como fiador de } \\
\text { Pedro de Moreyra }\end{array}$ & $\begin{array}{l}\text { Anton de don } \\
\text { Benito, alcalde } \\
\text { ordinario }\end{array}$ \\
\hline 35 & & Civil & $\begin{array}{c}\text { Remate del oficio de } \\
\text { regidor y alférez }\end{array}$ & $\begin{array}{c}\text { Capitán Andres de } \\
\text { Figueroa }\end{array}$ & don Felipe Reyes & $\begin{array}{l}\text { Pedro Gomez de } \\
\text { Aguiar, alcalde }\end{array}$ \\
\hline 36 & & Civil & $\begin{array}{c}\text { Dos carretas a la ciudad de } \\
\text { Santa Fe }\end{array}$ & $\begin{array}{l}\text { capitán Pedro } \\
\text { Rodríguez }\end{array}$ & Juana de Maidana & $\begin{array}{l}\text { Crespo Flores, } \\
\text { lugarteniente y } \\
\text { capitán a guerra }\end{array}$ \\
\hline 37 & 1664 & Criminal & $\begin{array}{l}\text { Heridas al indio llamado } \\
\text { Martin de su encomienda }\end{array}$ & $\begin{array}{c}\text { Protector de naturales } \\
\text { Gabriel López de } \\
\text { Arriola, en nombre del } \\
\text { dicho Juan }\end{array}$ & $\begin{array}{l}\text { Alférez Antonio de } \\
\text { Miranda }\end{array}$ & $\begin{array}{l}\text { Pedro Gómez de } \\
\text { Aguiar }\end{array}$ \\
\hline 38 & 1664 & Civil & $\begin{array}{c}\text { Confiscación de bienes del } \\
\text { reverendo padre predicar } \\
\text { fray... }\end{array}$ & Antonio de Mura & Deuda & $\begin{array}{l}\text { Capitán Crespo } \\
\text { Flores corregidor, } \\
\text { lugarteniente y } \\
\text { capitán a guerra }\end{array}$ \\
\hline
\end{tabular}




\begin{tabular}{|c|c|c|c|c|c|c|}
\hline 39 & & Civil & Oficios vendibles & ------ & Institucional & $\begin{array}{c}\text { Nicolas Pessoa de } \\
\text { Figueroa, } \\
\text { lugarteniente }\end{array}$ \\
\hline 40 & & Criminal & Heridas a Juan de Sosa & ----- & Persona & $\begin{array}{l}\text { Juan Diaz Moreno, } \\
\text { alcalde }\end{array}$ \\
\hline 41 & 1656 & Civil & Indio reservado & $\begin{array}{c}\text { El protector de } \\
\text { naturales, Domingo de } \\
\text { Peralta en } \\
\text { representación del } \\
\text { indio Matheo }\end{array}$ & $\begin{array}{c}\text { Fernando Gómez } \\
\text { Duran }\end{array}$ & $\begin{array}{l}\text { Capitán Nicolás } \\
\text { Pessoa de } \\
\text { Figueroa, } \\
\text { lugarteniente y } \\
\text { justicia mayor }\end{array}$ \\
\hline 42 & & Civil & $\begin{array}{l}\text { Conflicto entre herederos } \\
\text { por herencia }\end{array}$ & $\begin{array}{c}\text { Felipa de Burgos (hija } \\
\text { de Luis de Burgos y } \\
\text { Victoria de..., } \\
\text { adoptada por el } \\
\text { difunto) }\end{array}$ & $\begin{array}{l}\text { doña Juana de } \\
\text { Luxan mujer viuda } \\
\text { de Burgos }\end{array}$ & $\begin{array}{l}\text { Antonio de Soto, } \\
\text { alcalde ordinario }\end{array}$ \\
\hline 43 & 1665 & Civil & Pago de deudas & $\begin{array}{c}\text { Pedro Rodríguez de } \\
\text { Gama }\end{array}$ & Domingo del Barrio & $\begin{array}{l}\text { Juan Díaz Moreno, } \\
\text { alcalde }\end{array}$ \\
\hline 44 & & Civil & $\begin{array}{c}\text { Conflicto por entrega de } \\
\text { carretas y bueyes en Santa } \\
\text { Fe }\end{array}$ & Juan de Saavedra & $\begin{array}{c}\text { Ambrosio de } \\
\text { Acosta }\end{array}$ & $\begin{array}{l}\text { Capitán Flores, } \\
\text { justicia mayor }\end{array}$ \\
\hline 45 & & Civil & Demanda por bueyes & $\begin{array}{c}\text { Fray Gerónimo de } \\
\text { Elpesso }\end{array}$ & Rodrigo Díaz & $\begin{array}{l}\text { Flores capitán, } \\
\text { justicia mayor }\end{array}$ \\
\hline 46 & & Civil & $\begin{array}{c}\text { Testamentaria de Gabriel } \\
\text { de Esquivel }\end{array}$ & Familia & & ---- \\
\hline 47 & 1670 & Civil & $\begin{array}{c}\text { Causa dos carretas y diez } \\
\text { bueyes }\end{array}$ & $\begin{array}{l}\text { Ambrosio de Acosta y } \\
\text { el capitán Manuel } \\
\text { Cabral de Alpoin } \\
\end{array}$ & Juan de Saavedra & $\begin{array}{l}\text { Capitán Flores, } \\
\text { justicia mayor }\end{array}$ \\
\hline 48 & & & $\begin{array}{l}\text { Testamento de Antonia } \\
\text { Toledo }\end{array}$ & Theodora Ramírez & & \\
\hline 49 & & Civil & $\begin{array}{c}\text { Carta de obligación por } \\
\text { ganado vacuno que debía } \\
\text { pasar a la ciudad de } \\
\text { Asunción }\end{array}$ & $\begin{array}{l}\text { Cristóbal González } \\
\text { vecino de Santa Fe }\end{array}$ & $\begin{array}{c}\text { Domingo de } \\
\text { Quintana, vecino } \\
\text { del puerto de } \\
\text { Buenos Aires } \\
\end{array}$ & $\begin{array}{l}\text { Sebastian Crespo } \\
\text { Flores, teniente }\end{array}$ \\
\hline 50 & & Civil & Tasación de bienes & $\begin{array}{c}\text { Ana Fernández mujer } \\
\text { legitima de Pedro } \\
\text { Bargas }\end{array}$ & & $\begin{array}{l}\text { Juan Diaz de } \\
\text { Almiron, alcalde }\end{array}$ \\
\hline 51 & 1660 & Civil & $\begin{array}{l}\text { Donación de una mulata } \\
\text { esclava, María Inés por } \\
\text { quinientas cabezas de } \\
\text { ganado, res y otras obejas }\end{array}$ & Familia & & \\
\hline 52 & 1660 & Civil & Poder para representar & Don Esteban García & & \\
\hline 53 & 1660 & civil & $\begin{array}{c}\text { Nombramiento de } \\
\text { corregidor }\end{array}$ & Institucional & & $\begin{array}{l}\text { Felipe Diaz de } \\
\text { Agüero, alcalde }\end{array}$ \\
\hline 54 & 1660 & civil & Indios desamparados & $\begin{array}{c}\text { Al reverendo padre de } \\
\text { San Francisco Joan de } \\
\text { Garay }\end{array}$ & Encomienda & $\begin{array}{l}\text { Felipe Diaz de } \\
\text { Agüero, alcalde }\end{array}$ \\
\hline 55 & 1660 & civil & $\begin{array}{l}\text { Ausencia de indios en la } \\
\text { ciudad de Santa Fe }\end{array}$ & Encomienda & & $\begin{array}{l}\text { Miguel de Biegol, } \\
\text { teniente de } \\
\text { gobernador }\end{array}$ \\
\hline 56 & & Civil & $\begin{array}{c}\text { Carta de obligación de } 660 \\
\text { ganados }\end{array}$ & Juan Barreto & $\begin{array}{l}\text { Martín de } \\
\text { Chavarría }\end{array}$ & $\begin{array}{l}\text { Francisco de } \\
\text { Villanueva, teniente } \\
\text { de gobernador }\end{array}$ \\
\hline 57 & 1668 & civil & $\begin{array}{c}\text { Bienes de Bartolomé de } \\
\text { Ledesma en litigio por su } \\
\text { heredera }\end{array}$ & Tierra & & $\begin{array}{c}\text { Francisco de } \\
\text { Villanueva teniente } \\
\text { de gobernador }\end{array}$ \\
\hline 58 & & civil & Carta de obligación & Juan de Vallejos & & $\begin{array}{l}\text { Pedro Gomez de } \\
\text { Mesa alcalde } \\
\text { ordinario }\end{array}$ \\
\hline 59 & & civil & $\begin{array}{l}\text { Deuda de tres caballos de } \\
\text { la otra banda del Paraná }\end{array}$ & Domingo de Oroño & Jerónimo Peres & Alcalde ordinario \\
\hline 60 & 1669 & Civil & $\begin{array}{l}\text { Litigio por la mitad de un } \\
\text { solar }\end{array}$ & Miguel de Isaurralde & Ascencio Moreyra & $\begin{array}{l}\text { Pedro Gomez de } \\
\text { Mesa, alcalde } \\
\text { ordinario }\end{array}$ \\
\hline 61 & & Civil & $\begin{array}{l}\text { Litigio por los bienes de } \\
\text { Domingo Cabrera }\end{array}$ & Familia & $\begin{array}{l}---- \\
\end{array}$ & Alcalde ordinario \\
\hline 62 & & Civil & Demanda iniciada por & Domingo & $\begin{array}{l}\text { Adriano de } \\
\text { Esquibel }\end{array}$ & $\begin{array}{l}\text { Alcalde ordinario } \\
\text { Victor Figueroa }\end{array}$ \\
\hline 63 & & Criminal & Querella criminal & Persona & & ---- \\
\hline 64 & & Civil & Querella por la calumnia & ... Correa & Pablo de la Sierra & ----- \\
\hline 65 & & Civil & Demanda & Domingo de Acosta & & $\begin{array}{l}\text { Victor de Figueroa, } \\
\text { alcalde ordinario }\end{array}$ \\
\hline
\end{tabular}


Fátima VALENZUELA y Fernando POZZAGLIO. Redescubrimiento de los pleitos judiciales de una temprana sociedad colonial. Corrientes, Río de la Plata (1588-1680).

\begin{tabular}{|c|c|c|c|c|c|c|}
\hline 66 & 1670 & Civil & Pedido de ganado vacuno & $\begin{array}{l}----- \\
\end{array}$ & & $\begin{array}{l}\text { Corregidor Alonso } \\
\text { Delgadillo }\end{array}$ \\
\hline 67 & 1671 & Civil & $\begin{array}{l}\text { Pedido y alistamiento de } \\
\text { indios mitayos }\end{array}$ & \multicolumn{2}{|c|}{$\begin{array}{l}\text { Se pide el envío de } 150 \text { indios todos mosos } \\
\text { en armas para el puerto de Buenos Aires }\end{array}$} & $\begin{array}{l}\text { Alonso Delgadillo y } \\
\text { Atienza corregidor y } \\
\text { justicia mavor }\end{array}$ \\
\hline 68 & 1671 & Civil & Ganado vacuno & $\begin{array}{l}\text { Manuel Cabral del } \\
\text { Alpoin }\end{array}$ & $\begin{array}{l}---- \\
\end{array}$ & $\begin{array}{c}\text { Francisco de } \\
\text { Villanueba, } \\
\text { corregidor y justicia } \\
\text { mayor }\end{array}$ \\
\hline 69 & 1671 & Civil & $\begin{array}{c}\text { Bienes de Baltazar Flores } \\
\text { en disputa }\end{array}$ & Gabriel de Toledo & $\begin{array}{c}---- \\
\end{array}$ & $\begin{array}{l}\text { Blas de Arias, } \\
\text { alcalde ordinario }\end{array}$ \\
\hline 70 & 1678 & Civil & $\begin{array}{l}\text { Embargo por pago de } \\
\text { caballos y peón }\end{array}$ & Juan de Sosa & Hernando Díaz & $\begin{array}{l}\text { Alcalde ordinario } \\
\text { Blas de Arias }\end{array}$ \\
\hline 71 & 1671 & Civil & $\begin{array}{l}\text { Prisión de Pedro de } \\
\text { Moreyra }\end{array}$ & $\begin{array}{l}\text { Juan Gómez y } \\
\text { Francisco Gómez }\end{array}$ & $\begin{array}{ll}---- \\
\end{array}$ & $\begin{array}{l}\text { Alcalde ordinario } \\
\text { Díaz Rodríguez }\end{array}$ \\
\hline 72 & $\begin{array}{l}1647- \\
1657\end{array}$ & Civil & Conflicto por un solar & Juan Gómez de Sosa & ----- & $\begin{array}{l}\text { Alonso delgadillo y } \\
\text { Atienza. Corregidor } \\
\text { y lugarteniente }\end{array}$ \\
\hline 73 & 1761? & Civil & $\begin{array}{l}\text { Conflicto por vaquerías } \\
\text { realizadas por los indios de } \\
\text { pueblos de indios }\end{array}$ & $\begin{array}{c}\text { Juan Ramírez de } \\
\text { Orellana en nombre de } \\
\text { Manuel Cabral de } \\
\text { Alpoin }\end{array}$ & $\begin{array}{l}\text { Sebastián Crespo } \\
\text { Flores }\end{array}$ & Llega a la audiencia \\
\hline 74 & $\begin{array}{l}1670- \\
1671\end{array}$ & Civil & Conflicto por ganado & $\begin{array}{l}\text { Hernando de Gamarra } \\
\text { y Manuel de Melgarejo }\end{array}$ & $\begin{array}{ll}----- \\
\end{array}$ & $\begin{array}{c}\text { Alonso Delgadillo y } \\
\text { Atienza, corregido y } \\
\text { lugarteniente }\end{array}$ \\
\hline 75 & 1677 & Civil & $\begin{array}{c}\text { Paso sin licencia de } 60 \\
\text { indios de Yaguaron y dos } \\
\text { mil cabezas de ganado }\end{array}$ & $\begin{array}{ll}----- \\
\end{array}$ & $\begin{array}{l}\text { Manuel de } \\
\text { Melgarejo }\end{array}$ & $\begin{array}{c}\text { Alonso Delgadillo y } \\
\text { Atienza, corregidor } \\
\text { y lugarteniente }\end{array}$ \\
\hline 76 & & Civil & $\begin{array}{l}\text { Indios fugados de la } \\
\text { reducción de Itati }\end{array}$ & Encomienda & ----- & $\begin{array}{l}\text { Alonso Delgadillo y } \\
\text { Atienza, corregidor } \\
\text { y lugarteniente }\end{array}$ \\
\hline 77 & 1670 & Civil & $\begin{array}{l}\text { Visita a los indios de } \\
\text { Candelaria de Ohoma }\end{array}$ & Encomienda & ----- & Teniente \\
\hline 78 & 1670 & Civil & $\begin{array}{c}\text { Visita de indios a Santiago } \\
\text { Sánchez }\end{array}$ & Encomienda & $\begin{array}{ll}---- \\
\end{array}$ & Teniente \\
\hline 79 & 1671 & Civil & Visita a Santa Lucia & Encomienda & ----- & Ambrosio de Acosta \\
\hline 80 & 1671 & Civil & Visita & Encomienda & ----- & Teniente \\
\hline 81 & 1671 & Civil & Visita a Santiago Sanchez & Encomienda & ------ & Alonso Delgadillo \\
\hline 82 & 1672 & Civil & $\begin{array}{l}\text { Visita a Candelaria de } \\
\text { Ohoma }\end{array}$ & Encomienda & $\begin{array}{c}---- \\
\end{array}$ & $\begin{array}{l}\text { Alonso Delgadillo y } \\
\text { Atienza, corregidor } \\
\text { y justicia mayor }\end{array}$ \\
\hline 83 & 1672 & Civil & Visita a Itaty & Encomienda & ----- & $\begin{array}{l}\text { Francisco de } \\
\text { Villanueba, } \\
\text { lugarteniente, } \\
\text { justicia mayor y } \\
\text { capitán a guerra }\end{array}$ \\
\hline 84 & 1672 & Civil & $\begin{array}{c}\text {-Encomienda- } \\
\text { Reclamo porque no pagan } \\
\text { la tasa correspondiente }\end{array}$ & $\begin{array}{l}\text { Alexandro de Aguirre } \\
\text { encomendero }\end{array}$ & ---- & $\begin{array}{l}\text { Alonso Delgadillo y } \\
\text { Atienza corregidor y } \\
\text { justicia mayor }\end{array}$ \\
\hline 85 & & Civil & $\begin{array}{l}\text { Conflicto por una } \\
\text { testamentaria }\end{array}$ & $\begin{array}{l}\text { Francisco González de } \\
\text { Santa Cruz }\end{array}$ & Juan de Osado & $\begin{array}{l}\text { Francisco de } \\
\text { Villanueba, } \\
\text { lugarteniente, } \\
\text { justicia mayor y } \\
\text { capitán a querra }\end{array}$ \\
\hline 86 & 1672 & Civil & $\begin{array}{l}\text { Deuda de cabezas de } \\
\text { ganado }\end{array}$ & ---- & $\begin{array}{c}\text { Pedro de Moreyra } \\
\text { alcalde de Santa } \\
\text { Hermandad }\end{array}$ & $\begin{array}{c}\text { Alonso Delgadillo, } \\
\text { corregidor y justicia } \\
\text { mayor }\end{array}$ \\
\hline
\end{tabular}

Fig. 4: Catálogo de causas judicializadas. Fuente: Elaboración propia a partir de AGPC. Sala I. Judiciales. Tomo I-VI. 